\title{
Multiple roles of ephrins in morphogenesis, neuronal networking, and brain function
}

\author{
Amparo Palmer ${ }^{1}$ and Rüdiger Klein ${ }^{2}$ \\ Max-Planck Institute of Neurobiology, Department of Molecular Neurobiology, D-82152 Martinsried, Germany
}

Cell-to-cell communication during development and plasticity is controlled to a large extent by signaling events downstream of receptor tyrosine kinases (RTKs). Most RTKs bind soluble ligands, which are often produced at a distance from the RTK-expressing cells, and therefore these interactions typically mediate long-range communication. Eph receptors (or Ephs), instead, bind membrane-bound ephrin ligands expressed by neighboring cells and mediate short-range cell-to-cell communication. The influence of ephrin-Eph interaction on cell behavior depends on the cell type, but can in most cases be interpreted as repulsion of neighboring cells or of cellular processes, such as the neuronal growth cone. However, in some cases ephrin-Eph activation can have the opposite effect, that is, increased adhesion/attraction. One subclass of ephrins, the ephrinB ligands, are transmembrane proteins with intrinsic (so-called reverse) signaling properties (for review, see Kullander and Klein 2002). This complicates the interpretation of functional assays and genetic phenotypes, because manipulations intended to eliminate forward receptor function often have consequences for reverse signaling as well. This review summarizes the diverse biological roles of ephrins and Ephs in embryonic development, including patterning and morphogenetic processes of the nervous and vascular systems, and in the adult, such as synaptic plasticity. We further touch upon more recent observations on ephrin functions in neurogenesis, nervous system regeneration, and tumorigenesis. Our focus is on, but is not restricted to, recent findings using genetically amenable systems.

\section{General features of ephrins and Ephs}

During embryonic and postnatal development, cells need to respond to a changing environment, for example, the release of growth factors and morphogens, the mi-

Corresponding authors.

${ }^{1}$ E-MAIL palmer@neuro.mpg.de; FAX 49-89-8578-3152.

${ }^{2}$ E-MAIL rklein@neuro.mpg.de; FAX 49-89-8578-3152.

Article and publication are at http://www.genesdev.org/cgi/doi/10.1101/ gad.1093703. gration of neighboring cells, and the production of extracellular matrix proteins by differentiating cells. Through binding to their cognate protein ligands, receptor tyrosine kinases are sensors of such environmental changes and transmit information to the inside of the cell. Of all the RTKs in the human genome, Eph receptors constitute the largest subfamily, which probably arose through rather recent gene duplications. Its 13 members (in mammals) are subdivided based on sequence similarity and ligand-binding characteristics into an A-subclass (EphA1-EphA8) and a B-subclass (EphB1-EphB4, EphB6) with partially overlapping functions (for reviews, see Wilkinson 2001; Kullander and Klein 2002). Their ligands, the ephrins, are also subdivided into an A-subclass (ephrinA1-ephrinA5), which are tethered to the exoplasmic leaflet of the cell membrane by a glycosylphosphatidylinositol (GPI) anchor, and the B-subclass (ephrinB1-ephrinB3), which contain transmembrane and cytoplasmic regions. EphrinA ligands typically bind to EphA receptors, and ephrinB ligands bind to EphB receptors. The EphA4 receptor has a broader ligand-binding spectrum, as it can bind most ephrinA, as well as ephrinB2 and ephrinB3, but not ephrinB1, ligands.

The ephrin-Eph system is unique among the RTK family mainly for two reasons: First, ephrinB ligands (and perhaps also ephrinAs) not only induce signaling downstream of the Eph receptors (forward signaling), but also signal themselves into the cell that expresses them-referred to as reverse signaling (see below). Second, functional ephrin-Eph signaling might require the generation of a higher-order complex, and the quality of the signaling output exerted by higher-order clusters seems to be different from the one exerted by a receptor dimer (Stein et al. 1998). Structural data showed that Eph and ephrin interaction domains associate as a cyclic heterotetramer with 2:2 stoichiometry, arranged with the C termini perpendicular to the plane in opposite directions (Fig. 1; Himanen et al. 2001). Other features of Ephs and ephrins are likely to promote further oligomerization. These include the sterile $\alpha$ motif (SAM) oligomerization domain located in the Eph cytoplasmic region, and ephrin and Eph C-terminal PDZ-domain target sites, which may bind scaffolding proteins (Fig. 1). 
Palmer and Klein

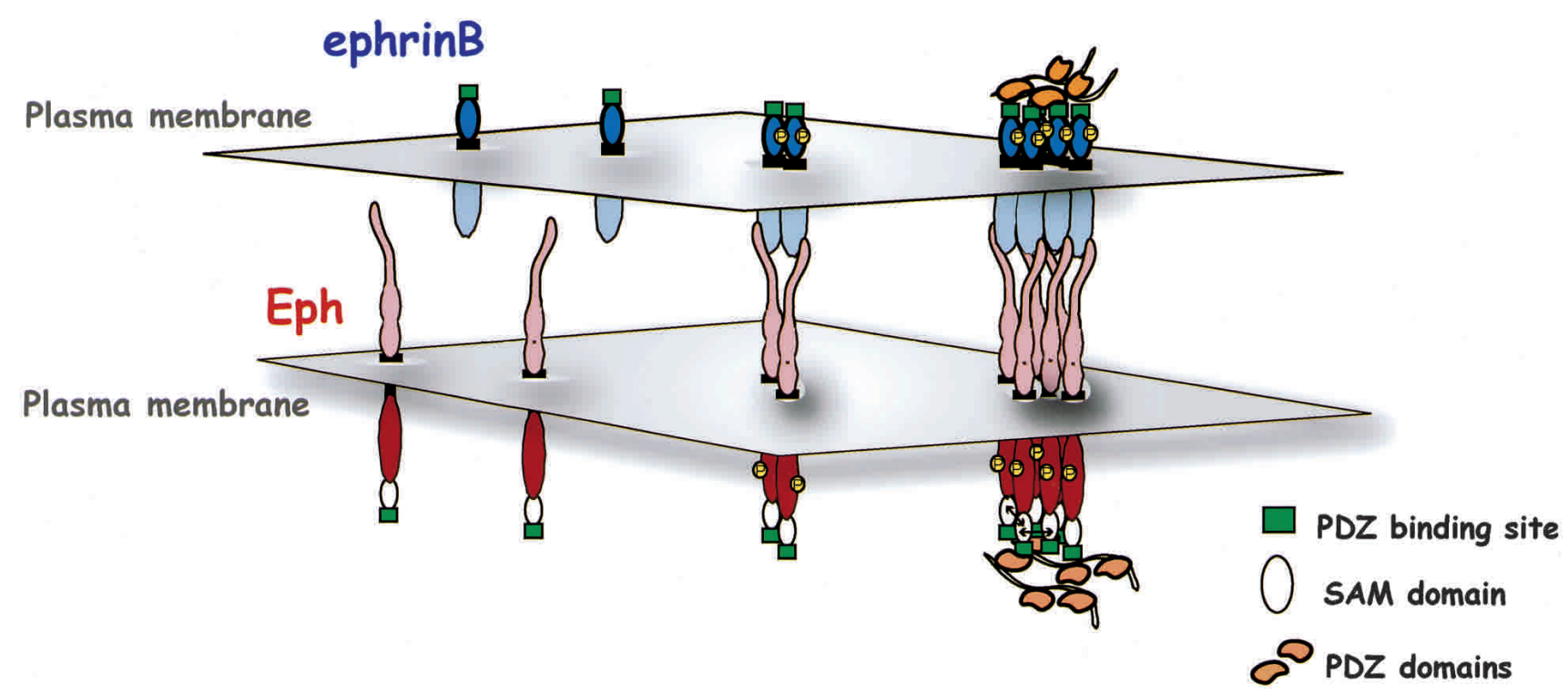

Figure 1. The ephrin-Eph signaling complex. Membrane attachment of both Ephs and ephrins provides a mechanism whereby interactions between receptors and ligands occur only at sites of cell-cell contact, leading to the multimerization of both molecules to distinct clusters in their respective plasma membranes. Each Eph receptor binds an ephrinB ligand by the insertion of an extended ephrin loop into a channel at the surface of the receptor. Two Eph-ephrin dimers then join to form a tetramer, in which each ligand interacts with two receptors and each receptor interacts with two ligands. Additional higher-order clustering might occur via the SAM domains in the receptors and C-terminal PDZ target sites in both ephrins and Ephs.

\section{Oocyte maturation}

During sexual reproduction in animals, oocytes arrest at the first meiotic prophase and resume meiotic maturation in response to sperm or somatic cell signals. Considerable advances have been made in recent years concerning the regulation of intracellular events in the oocyte that will lead to maturation. One example is the activation of MAPK cascades resulting in the activation of the maturation promoting factor (MPF; Nebreda and Ferby 2000). On the contrary, very little is known about the events at the surface that trigger maturation. In many invertebrates, among them the worm Caenorhabditis elegans, sperm are the source of the signal for oocyte maturation and ovulation. The identity of that signal, a 14-kD peptide called major sperm protein (MSP), was recently discovered (Miller et al. 2001), but the receptors for this protein remained unknown. The same group recently identified VAB-1, the C. elegans Eph receptor, as one of the receptors for MSP, as part of a sperm-sensing control mechanism (Miller et al. 2003). VAB-1 signaling suppresses oocyte maturation and MAPK activation, and MSP acts as an antagonizer of VAB-1 by competing with ligand binding (Fig. 2). However, MSP appears to signal not only through VAB-1dependent but also VAB-1-independent pathways, because microinjection of MSP in the uterus of unmated $v a b-1$ mutants still promoted oocyte maturation. Of the four ephrins in the C. elegans genome, ephrinB2 (EFN-2) seems to be the ligand responsible for the negative regulation of maturation. Arrested oocytes are surrounded in the proximal gonad arm by smooth muscle-like gonadal sheath cells, which also negatively regulate oocyte maturation, possibly by signaling through gap junctions (Hall et al. 1999). Sheath-cell-expressed POU-homeoprotein CEH-18 is required for complete inhibition of maturation. Thus, VAB-1 and CEH-18 define parallel and partially redundant pathways required for the inhibition of oocyte maturation, and both act together to negatively regulate MAPK activation. Moreover, a process of sheath cell contraction facilitates ovulation and is also induced by MSP. In this case the authors show that VAB-1, in an ephrin-independent manner, is required for MSP-induced sheath cell contractions (Fig. 2). In agreement with this study in C. elegans, Eph receptors are known, from studies in mammalian cultured cells, to have an inhibitory effect on MAPK signaling, and this suppression is dependent on regulatory motifs and SH2-binding sites on the receptor. Recent work indicated a correlation between neurite retraction and the ability of mutant forms of EphB2 to down-regulate Ras/MAPK signaling (Tong et al. 2003 and references within).

\section{Early morphogenesis}

The notochord is an axial structure of mesodermal origin and is one of the earliest embryonic structures to be formed. It plays a critical role in patterning of ectodermal and mesodermal tissues (e.g., neural tube and somatic derivatives). Early studies using dominant-negative strategies showed some evidence for involvement of Eph/ephrins in gastrulation events in Xenopus embryos (Winning et al. 1996; Jones et al. 1998; for review, see Holder and Klein 1999). Ectopic overexpression of dominant-negative soluble ephrinB in zebrafish causes defects in the morphology of the notochord and prechordal plate 


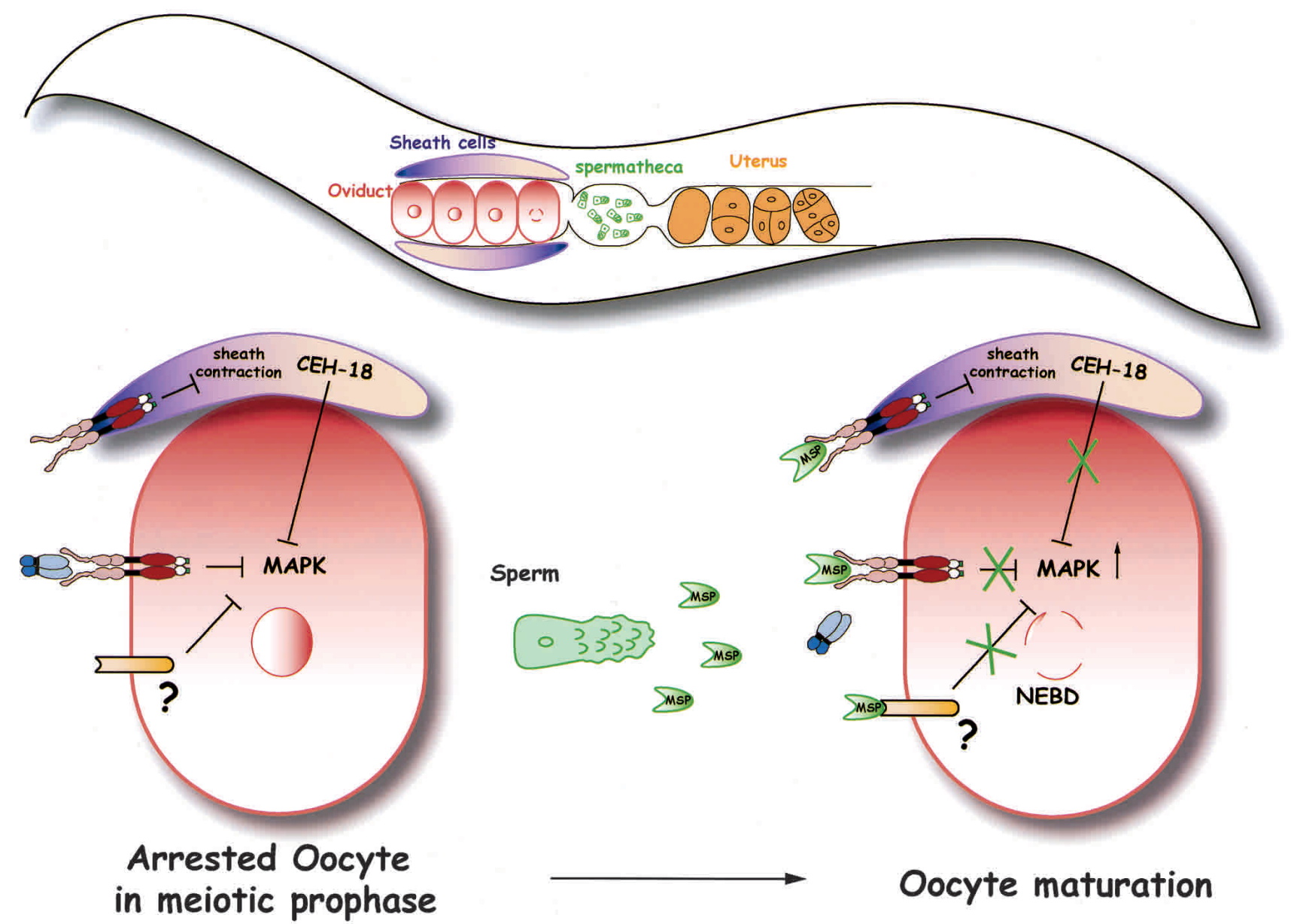

Figure 2. Signaling by Eph receptors controls oocyte maturation. In C. elegans, oocyte maturation occurs in the more proximal position in the gonad arm. Sheath cell contraction helps the mature oocyte to enter the lumen of the spermatheca, where fertilization will occur. The fertilized egg moves then from the spermatheca to the uterus, where it will complete meiotic division. Oocytes are arrested at meiotic prophase and meiotic maturation involves nuclear envelope breakdown (NEBD), cortical cytoskeletal reorganization, MAPK activation, and meiotic spindle assembly. Signaling by a EFN-2/VAB-1 receptor and a CEH-18-dependent pathway(s) negatively regulates oocyte maturation and MAPK activation. Sperm disrupt these inhibitory pathways by releasing MSP, which binds to VAB-1 receptor and to other unidentified receptors in the oocyte. MSP binding antagonizes both VAB-1 and CEH-18-dependent signaling, promoting MAPK activation and maturation. In somatic sheath cells, VAB-1 is required for MSP-mediated contractions, a process that does not involve ephrin binding. Therefore, VAB-1 has an ephrin-dependent function in the germ line and an ephrinindependent function in sheath cells.

by the end of gastrulation, in a manner suggestive of defects in cell migration (Chan et al. 2001). EphA2 gene disruption studies in mice provided the first genetic evidence for a possible role of the Eph/ephrin system in regulating tail notochordal cell positioning (Naruse-Nakajima et al. 2001). In embryonic day 10.5 (E10.5) wildtype embryos when the neuropore has just closed and the tail bud is formed, newly generated notochordal cells expressing EphA2 are excluded from the territory of the tail bud where ephrinA1 is expressed. In ephA2 gene trap mutants, notochordal cells aberrantly invade the tail and form bifurcated notochords, resulting in morphological abnormalities of the tail as early as E12.5.

\section{Segmentation}

Segmentation is a mechanism used by both vertebrates and invertebrates to generate regionally distinct struc- tures starting from uniform fields. Segmentation occurs in vertebrates at two regions: the paraxial mesoderm, which gives rise to the somites, and in the hindbrain. Eph receptors and ephrins are expressed in both hindbrain neural plate and paraxial mesoderm and functional analysis of receptor signaling in zebrafish and Xenopus indicates that this signaling is crucial for normal development of segmental boundaries in both regions of the embryo.

\section{Paraxial mesoderm segmentation}

The paraxial mesoderm is formed by thick bands of mesodermal cells that extend on both sides of the notochord from the base of the head into the tail. As the neural tube closes, the paraxial mesoderm is separated into blocks of cells (somitomeres) that will give rise to the somites. The somites later determine the migration paths of neu- 
ral crest cells and spinal nerve axons and eventually give rise to the vertebrae and ribs, the dermis of the dorsal skin, the skeletal muscles of the back, and the skeletal muscles of the body wall and limbs. In previous work, Eph/ephrin signaling was shown to be involved both in the initial segmentation of the presomitic mesoderm as well as in the division of the somites into anterior and posterior halves. EphA4 is expressed in the anterior half and ephrinB2 in the posterior (Durbin et al. 1998; for review, see Tepass et al. 2002). One important event in this process is the transition of the loosely compacted somitomere to an epithelial somite. Little is known about the regulation of this cellular transition. In zebrafish, EphA4 is expressed in the rostral presomitic mesoderm, where epithelialization occurs. Removal of the ectoderm covering the somites and the midline ectoderm, which results in cells with irregular morphology and failure to form somites, leads to loss of expression of EphA4 in the segmental plate, raising the possibility that EphA4 might contribute to somite segmentation (Schmidt et al. 2001). The identity of the signals capable of inducing EphA4 expression remains unknown. In the mouse, the transcription factor Mesp is expressed during somitogenesis in the presomitic mesoderm and is required for the establishment of rostral properties within the somites (Saga et al. 1997). In mouse mutants with reduced activity of Mesp, the expression of EphA4 in the anterior part of the somites is unaffected, and initially somites segregate normally. However, they soon fuse again, indicating that Eph/ephrin signaling could be sufficient for intersomitic cleft formation but not for the cleft maintenance (Nomura-Kitabayashi et al. 2002). The observation that mice lacking EphA4 have no defects in somitic segmentation suggests a possible redundancy with other family members.

\section{Hindbrain and forebrain segmentation}

The hindbrain develops a segmental pattern consisting of seven segments or rhombomeres (r1-r7) that specifies where certain nerves originate and how different streams of neural crest cells migrate into the branchial arches. The organization is such that cell movement between rhombomeres is restricted because of distinct cellular properties of $\mathrm{r} 3 / \mathrm{r} 5$ compared with $\mathrm{r} 2 / \mathrm{r} 4 / \mathrm{r} 6$. Complementary expression of Ephs and ephrins in alternate rhombomeres has led to the proposal that restriction of cell intermingling might be achieved, at least in part, by expression of Ephs and ephrins in rhombomere-specific patterns under the control of segmentally expressed transcription factors (for review, see Cooke and Moens 2002; Tepass et al. 2002). Overexpression studies have suggested a role of EphA4/ephrinB2 signaling in the segmentation of the developing Xenopus and zebrafish hindbrain (for review, see Tepass et al. 2002). Genetic analyses in zebrafish have recently implicated another receptor for ephrinB2, EphB4, in cell sorting and boundary formation (Cooke et al. 2001). Embryos with a null mutation in valentino (val, bzip transcription factor homolog to mouse kreisler) lack segmentation of the cau- dal hindbrain. Elegant genetic mosaic experiments showed the inability of $\mathrm{val}^{-}$mutant cells to contribute to r5 and 6 of wild-type embryos. In these mosaic experiments, $\mathrm{val}^{-}$patches express ephrinB2 and do not invade the territory of EphB4a expression, suggesting that Eph/ ephrin signaling could be responsible for such a repulsive effect. Val function is, in fact, required for activation of EphB4a expression and repression of ephrinB2a expression in $r 5$ and $r 6$, thereby restricting ephrinB2a to $r 4$ and r7. In val mutants, ephrinB2a is expressed throughout $\mathrm{r} 4$ to r7, whereas EphB4a and EphA4 are not longer expressed. Blocking bidirectional signaling by overexpression of EphB4a or a soluble form of ephrinB2a in $\mathrm{val}^{-}$ donor cells resulted in intermingling of $\mathrm{Val}^{-}$patches with EphB4a-expressing cells. In many occasions, Ephephrin signaling results in contact repulsion, suggesting that the formation of segments results from mutual repulsion or deadhesion (loss of cell-to-cell contacts) responses at the segment interface preventing each population from invading the other.

\section{Guidance of migrating cells}

\section{Neural crest cell migration}

Neural crest cells originate at the dorsal region of the neural tube and migrate extensively to generate many kinds of differentiated cells, including most of the neurons and glia of the peripheral nervous system, the craniofacial skeleton, and nearly all the pigment cells (for review, see Kalcheim 2000). The fate of the neural crest cells depends on where the cells migrate and settle. Like neuronal growth cones, neural crest cells migrate along specific pathways to their destinations. Eph receptors and their ligands have been shown to participate in the spatial restriction of the migration of some of the domains of neural crest cells, specifically trunk and branchial neural crest cells.

The trunk neural crest includes cells that will form the dorsal root and sympathetic ganglia. In the trunk of the chick embryo, these cells migrate along two distinct pathways. One fraction of the neural crest cells /1st wave), migrates ventrolaterally through the somites and responds to cues present in these structures that restrict migration to the anterior half of each somite. EphrinB1 and ephrinB2 (in chick and mouse, respectively) expressed in the posterior part of the somites act as repulsive cues for the migratory trunk neural crest cells expressing EphB receptors (Krull et al. 1997; Wang and Anderson 1997). Mutant mice lacking Delta-1 show abnormal migration of neural crest cells, with invasion of the caudal part of the somites. Interestingly, these mice also show reduced expression of both ephrinB2 and EphB2, suggesting that Notch/Delta signaling might be important for maintaining normal levels of EphB2 and ephrinB2 in the neural crest cells and somites, respectively (De Bellard et al. 2002). A second wave of neural crest cells migrates later from the neural tube and invades the dorsolateral pathway, between the dermomyotome and the overlying ectoderm, to colonize the skin. 
These cells are specified as melanoblasts prior to entering the dorsolateral pathway and are the only neural crest cells that possess the ability to migrate in this pathway. Recent work from Santiago and Erickson (2002), has shown that also these cells use Eph receptors and ephrin ligands as migratory cues. The dorsolateral path expresses ephrins at the time when neural crest cells expressing Eph receptors migrate ventrally, thereby blocking early dorsolateral migration. Impairment of EphB function results in inappropriate early neural crest cell migration into the dorsolateral pathway. Surprisingly, ephrins are still expressed in the dorsolateral pathway at the time when the second wave of migration takes place and appear to stimulate the migration of melanoblasts in this pathway. The intracellular mechanisms that would convert the ephrin signal from repulsion to attraction in the dorsolateral pathway are unknown at present.

The migration of branchial neural crest cells is also strictly guided by cues expressed in the paths through which these cells migrate, and this migration relates to the segmental organization of the hindbrain (for review, see Holder and Klein 1999; Kullander and Klein 2002). The expression of Eph receptors on cranial neural crest cells (EphA4, EphB1, and EphB3) and ephrinB2 in branchial arches suggests again a repulsive mechanism operating for crest guidance in mouse embryos. Null mutant mice for ephrinB2 show that this ligand is essential for branchial arch morphogenesis (Adams et al. 2001). Late migration of cranial neural crest cells is severely affected in these mice, with no neural crest cells migrating in the second arch. Interestingly, the neural crest cell migration defect in ephrinB2-null mutants was rescued in mice homozygous for a knock-in allele of ephrinB2 specifying a mutant ephrinB2 lacking its cytoplasmic domain (ephrinB2 $\Delta \mathrm{C}$ ), suggesting that ephrinB2 does not engage in reverse signaling in this context but acts as a repulsive ligand for the Eph receptor expressed in the neural crest cells.

\section{Cerebellar granule cell migration}

The studies of Flanagan and coworkers (Lu et al. 2001) provide functional evidence for an effect of ephrinB reverse signaling on cerebellar granule cell migration. SDF-1 and its receptor CXCR4 are required for normal granule cell migration. SDF-1 is expressed during embryonic stages in the pia mater overlying the cerebellum, and prevents premature inward migration of cerebellar granule cells by attracting them toward the pia (Ma et al. 1998; Zou et al. 1998; McGrath et al. 1999). SDF-1 continues to be expressed in the pia at postnatal stages when the massive inward migration of cerebellar granule cells takes place. The mechanism proposed for blocking the attractive function of SDF-1 involves reverse signaling downstream of ephrinB ligands. Reverse signaling induced by soluble EphB2-Fc specifically inhibits the attractive effect of soluble SDF-1 in the migration of cultured cerebellar granule cells (Lu et al. 2001). EphrinB reverse signaling in this process is mediated by a cyto- plasmic protein, PDZ-RGS3, which binds constitutively to the PDZ-binding site of ephrin. PDZ-RGS3 inhibits heteromeric G-protein signaling downstream of SDF-1 through the GAP activity of its RGS domain. The time when EphB2 and ephrinB1 expression is up-regulated in granule cells correlates with the onset of migration in the mouse cerebellum, consistent with the idea that ephrinB1 reverse signaling allows inward migration by blocking SDF-1 (Karam et al. 2000). The expression ceases as soon as the migrating cells penetrate the Purkinje cell layer and enter the internal granular layer (IGL). Complementary expression patterns between EphA4 and some of the A-ephrin ligands suggest that Eph-ephrin signaling may participate in earlier patterning events of the cerebellum leading to ribbons of migrating granule cells and to the formation of a highly restricted Purkinje cell compartment (Lin and Cepko 1998; Karam et al. 2000).

\section{Epithelial cell migration}

The first studies that showed an involvement of Eph receptors and ephrinB ligands in the migration of epithelial cells came from the genetic analysis of the $V A B-1$ locus in C. elegans, which encodes the single Eph receptor. In null mutants for $V A B-1$, migration of epidermal cells during ventral enclosure of the epidermis is defective (George et al. 1998; Chin-Sang et al. 1999). On the ligand side, efn-1 mutants cause phenotypes weaker but otherwise similar to those elicited by vab-1 mutants. The fact that the efn-1;efn-2;efn-3 triple ligand mutant shows the same phenotype as the vab-1-null mutant suggests that these three ephrins might account for all signaling functions of the VAB-1 Eph receptor. The VAB-1/ EFN-1 signaling pathway appears to have some functional redundancy with a pathway involving the LARlike receptor tyrosine phosphatase PTP-3. Loss of function in $p t p-3$ causes low-penetrance defects in gastrulation and epidermal development similar to those of vab-1 (Harrington et al. 2002). Interestingly, the recent work from Chin-Sang et al. (2002) has shown that the fourth worm ephrin, EFN-4, has roles in embryonic morphogenesis independent of VAB-1 Eph receptor signaling and has identified a potential cross-talk between ephrins and Semaphorin signaling.

Another example of precise and spatially organized cell migration is the movement of intestinal epithelial stem cells that originate in the crypts and migrate toward the lumen of the mammalian intestine. These precursor cells commit to different cell lineages during their migration and undergo differentiation when reaching the top of the crypts. In the small intestine, absorptive, enteroendocrine, and goblet cells migrate toward the villus, while Paneth cells migrate toward the bottom of the crypt. The Wnt signaling pathway plays a central role in development of the intestinal epithelium (for review, see Brittan and Wright 2002), and aberrant activation may lead to polyp formation and eventually colorectal cancer (for review, see Fodde et al. 2001). Stimulation of the Wnt pathway leads to stabilization and translocation of 
$\beta$-catenin to the nucleus, where it associates with TCF transcription factors. EphB receptors and ephrins have been shown to be part of the genetic program activated by $\beta$-catenin/TCF in colorectal cancer cells. EphB2 and EphB3 receptor expression is up-regulated and ephrinB1 expression is down-regulated in response to Wnt signaling (van de Wetering et al. 2002). In a parallel study, Eph receptors and ephrinB ligands have been shown to be involved in the regulated migration and positioning of renewed cells in the adult intestine (Batlle et al. 2002). Disruption of ephB2 and ephB3 genes reveals that these receptors restrict cell intermingling between proliferative and differentiated cells and guide the proper location of different cell populations within the small intestinal epithelium of neonatal mice. The adult mouse intestine shows yet a more complex pattern of Eph/ephrin expression than the neonatal intestine, with receptor and ligand gradients along the crypt (Fig. 3) reminiscent of the gradients seen during formation of neuronal topographic maps (see below). The EphB2 receptor gradient along the crypt axis is required for the correct positioning of ephrinB1- and ephrinB2-expressing highly proliferative pre-

WT

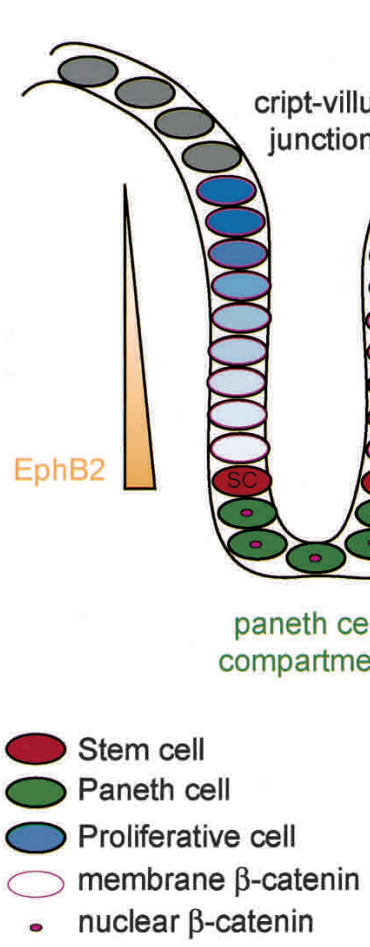

Figure 3. Ephs and ephrins restrict intermingling and allocate cell populations in the intestinal epithelium. Schematic representation of an adult small intestinal crypt. Stem cells (SC) are located around positions 4-6 near the base, giving rise to transient populations of proliferative cells. These cells migrate toward the villus to become cell-cycle-arrested at the crypt-villus junction, where they initiate differentiation. Paneth cells follow a downward migration path to occupy the bottom positions in the crypt immediately below the putative stem cell zone, where EphB3 is expressed. Proliferative cells in the crypt coexpress EphB2 receptor and their ligands ephrinB1 and ephrinB2 in an inverse, position-dependent pattern. EphB2 is expressed in a decreasing gradient toward the top of the crypt, whereas the expression of the ligands decreases gradually toward the bottom. In mice lacking EphB2 and EphB3 receptors, proliferative cells with high levels of ephrinB1/B2 invade the bottom of the crypt, and Paneth cells are found throughout the crypt. In these mutants, the nuclear localization of $\beta$-catenin at the bottom of the crypt is maintained, suggesting the presence of a non-cellautonomous process controlled by the position of cells along the crypt-villus axis. cursors. EphB3 receptor expression is restricted to cells located at the bottom of the crypts, immediately below the putative stem cell zone, including the Paneth cells and the crypt base columnar cells. EphB3-null mice howed striking defects in the localization of Paneth were distributed throughout the crypt. Proliferative cells located at the bottom of the crypts as well as all Paneth cells, accumulate high levels of nuclear $\beta$-catenin in a non-cell-autonomous fashion, suggesting the presence of a localized source of Wnt factors at the base of the crypts. Despite the extensive intermingling of cell types observed in ephB2/ephB3 mutant animals, nuclear -catenin remained restricted to cells at the bottom of the crypts. This might explain the normal maturation of the intestine in these mutants.

\section{Topographic mapping}

Many axonal connections in the brain, in particular sensory systems, are topographically organized such that neighborhood relationships are preserved from one neu-

$$
\mathrm{EphB2}^{-/-} \mathrm{EphB3}^{-/-}
$$

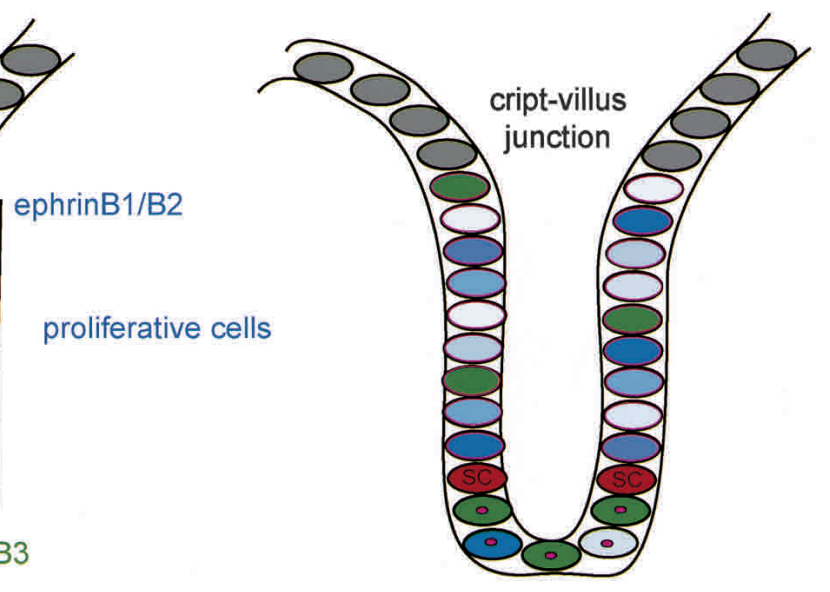

EphB3

ephrinB1/B2

proliferative cells

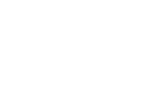


ronal population to another. In the visual system, retinal ganglion cells (RGCs) send their axons to the appropriate area in the midbrain, where the spatial organization in the retina is maintained. (The midbrain target is termed the tectum in chick and the superior colliculus, SC, in mammals.) This allows the spatially intact projection of visual images to the brain.

\section{Retinotopic mapping}

Anterior-posterior (A-P) topographic targeting of retinal axons is controlled by a graded distribution of EphAs and ephrinAs in retina and midbrain, respectively (for review, see Flanagan and Vanderhaeghen 1998; O'Leary and Wilkinson 1999; Wilkinson 2000; Klein 2001; McLaughlin et al. 2003a). Axons expressing EphA receptors at high density project to the anterior midbrain SC with low expression of ephrinA2/A5 repellents, whereas axons with low EphA density project to more posterior regions of the SC, where they encounter higher levels of ephrinA repellents. Genetic studies in the mouse demonstrated a functional requirement for ephrin/Eph gradients in retinotopic mapping. Loss of both ephrinA2 and ephrinA5 caused the disruption of topographic organization and suggested a model, in which gradients of repellents operate in combination with axon-axon competition in map formation. In mutant mice, retinal axons overshot the target area and projected to more posterior positions, consistent with the concept that ephrins act as posterior repellents. At the same time, the shift of one population of axons to ectopic sites in the SC increased the local competition with other axons at that site and caused further misprojections (Feldheim et al. 2000). On the receptor side, things are less clear, because Eph knockout studies have so far not revealed defects in retinotopic mapping comparable to those of ephrinA2/A5 mutants. Instead, targeted knock-in of ephA3 in subsets of RGCs, which disturbed EphA gradients in the retina, concomitantly caused projection errors of both ephA3overexpressing and wild-type RGCs (Brown et al. 2000). These findings provide strong evidence for competition between RGC axons and show that relative, rather than absolute, levels of EphA provide positional information.

Despite these significant breakthroughs, the findings on retinotopic mapping have become somewhat complicated and in part controversial (Yates et al. 2001; Knoll and Drescher 2002). Retinotopic mapping is studied using a variety of techniques in different species, which express different gradients of endogenous ephrin/Ephs. For example, the EphA3 receptor is asymmetrically expressed in the chick retina, whereas mouse retina expresses EphA3 uniformly; ephrinA2 expression shows a low-anterior-to-high-posterior gradient in the chick tectum, whereas in the mouse SC, ephrinA2 expression is confined to a medial stripe. Models of retinotopic mapping based on expression patterns of EphAs in the retina and ephrinAs in the midbrain have been challenged by the demonstration of graded expression of ephrinAs in the retina and of EphA receptors in the midbrain. Retinal ephrins appear to regulate the sensitivity of EphA- expressing retinal axons (for review, see Knoll and Drescher 2002). However, other functions seem plausible. Retinal ephrinAs may activate EphA receptors on tectal/SC cells and/or engage in reverse signaling into RGCs. Spatially restricted knockouts of ephrinAs in the retina versus superior colliculus will be required to solve these issues. The mechanism of retinotopic mapping is also not fully understood. In some species, like frogs and fish, RGC axons are targeted directly to their appropriate termination zone, where they develop terminal arborizations. In chick, cat, and rodents, it is debated whether or not the initial projection to the midbrain is topographically diffuse, with many axons making targeting errors and overshooting the termination zone. In this case, topographic connections are formed by axonal branches originating from the axon shaft. O'Leary and coworkers (Yates et al. 2001) recently proposed models in which the principle role of ephrinAs in chick retinotectal mapping is to inhibit branch formation along the overshooting segment of RGC axons posterior to their termination zone. In agreement with previous models, it was proposed that the ephrinA repellent gradient cooperates with other gradients, either a countergradient of another repellent or a parallel gradient of an attractant (for review, see Flanagan and Vanderhaeghen 1998; O'Leary and Wilkinson 1999; Wilkinson 2000; McLaughlin et al. 2003a). O'Leary and coworkers (Yates et al. 2001) modified the model and suggested the presence of either a countergradient of another branch repellent or a parallel gradient of a branch promoting factor.

Recent reports have shown that dorsoventral (D-V) topography is controlled by ephrinB/EphB signaling, in ways rather opposite to ephrinA/EphA-mediated A-P topography. EphB receptors are expressed in low-to-high $\mathrm{D}-\mathrm{V}$ gradients in the retina, and ephrinB1 is expressed in a low-to-high gradient along the lateral-medial (LM) axis of the optic tectum/SC. EphrinB ligand expression forms the opposite gradient (for review, see Pittman and Chien 2002). Unlike the A-P pattern, ventral axons expressing high levels of EphB project to targets with high ephrinB levels, inconsistent with repulsive interactions. Targeted disruption of ephB2 and ephB3 genes in mice caused a shift of ventral axon termination zones to more lateral regions of the SC with lower levels of ephrinB1, suggesting that, in wild-type mice, the ephrinB1 gradient attracts ventral axons (Hindges et al. 2002). Ectopic expression of ephrinB1 in the developing chick tectum suggests a bifunctional role of ephrinB1 as a repellent and attractant in DV retinotopic mapping (McLaughlin et al. 2003b; for review, see McLaughlin et al. 2003a). In the frog, dorsal axons expressing high levels of ephrinB ligands project to targets in the ventral tectum with high EphB1 levels. Blocking ephrinB/EphB interactions in vivo by application of exogenous EphB or expression of dominant-negative ephrinB eliminated retinal projections to the ventral tectum. In vitro stripe assays showed that dorsal, ephrinB-expressing axons preferred to grow on stripes of clustered EphB. Together, the data suggested that topographic mapping by dorsal axons to ventral tectum required the ephrinB cytoplasmic tail 
suggestive of ephrinB reverse signaling (Mann et al. 2002b).

Ephrin ligands and an Eph receptor are also required for visual system development in Drosophila (Dearborn et al. 2002). In the fly, the spatial arrangement of ommatidial units in the eye is preserved in a precise topographical order of connections to the brain. Topography is further maintained in the second-order optic ganglion, the medulla, in that neurons lined up in an outer disklike cortex project axons in a centripetal pattern into a central neuropil. The single Drosophila EPH receptor is expressed in a graded pattern in the medulla. Disruption of EPH expression by RNA interference, or by ectopic expression of wild-type or dominant-negative eph transgenes, disrupted axon topography. These findings point to a critical function for EPH activity in topographic mapping. Final proof for such a role of Drosophila EPH will, however, have to await the generation of genetic null mutants. Nevertheless, these observations suggest the presence of conserved mechanisms in the development of topographic mapping in vertebrate and invertebrate nervous systems.

\section{Vomeronasal projections}

Other topographic maps besides the retinotectal map require instructive signals from ephrins and Ephs, although the mode of action of this signaling family appears different. Neurons of the vomeronasal organ (VNO), a pheromone detection system of terrestrial vertebrates, send their axons to the accessory olfactory bulb (AOB) in a conserved topographic pattern. VNO axons with high ephrinA5 ligand expression project to regions of the AOB that express high levels of EphA6, and genetic ablation of ephrinA5 leads to topographic mapping errors in the vomeronasal system. These findings suggest that signaling by axonal ephrinA ligands present on axons promotes attraction, rather than repulsion. Indeed, when given the choice, VNO axons prefer to grow on EphA-Fc, rather than Fc substrates (Knoll et al. 2001b; for review, see Knoll and Drescher 2002). Topographic mapping has also been demonstrated in the limbic circuits, a system critical for learning, memory, and emotional behavior. Hippocampal neurons project topographically to their major subcortical projection target, the lateral septum. The expression patterns of EphA receptors and ephrinA ligands parallel that of the A-P retinotectal map, and transgenic expression of a dominant-negative isoform of EphA5 causes mistargeting of hippocampal axons, suggestive of a physiological role of EphA/ephrinA in this circuit (Yue et al. 2002 and references within).

\section{Segregated maps}

In addition to the formation of smooth topographic maps, ephrins and Ephs appear to be involved in the establishment of discontinuous, segregated maps. Connections between the thalamus and the neocortex are layer- specific. For example, in the primary somatosensory area of the neocortex, projections from the ventrobasal thalamus terminate in cortex layer 4, skip layer 5, and extend collaterals in layer 6. Interference with ephrinA/EphA interactions in in vitro sprout and branch formation assays suggests a role for ephrins in the establishment of layer-specific thalamocortical connections (Mann et al. 2002a). The cerebral cortical surface is parceled into functional areas that have specific patterns of incoming and outgoing connections. Within the rodent somatosensory cortex, each whisker is uniquely represented by groups of target neurons in the S1 region of the cortex, the so-called barrel field. Disruption of the ephrinA5 gene in mice did not alter the point-to-point thalamocortical connections, as shown by in vivo functional imaging (Prakash et al. 2000). It caused, however, distortions in the size of the barrels, suggesting that ephrinA5 could act as a positional label for within-area map formation (Vanderhaeghen et al. 2000). Different functional areas of the cerebral cortex, for example, medial versus somatosensory cortex, are innervated by different thalamic nuclei. Limbic thalamic neurons in laterodorsal nuclei normally avoid the sensorimotor cortex and project to the cingulate cortex. In ephrinA5-null mutants, limbic thalamic neurons formed additional aberrant projections to the sensorimotor cortex, which suggests that ephrinA5 acts as a guidance cue that restricts thalamic axons from connecting with inappropriate neocortical areas (Uziel et al. 2002). In primates, the innervation of the visual cortex by thalamic axons is especially segregated and can be defined by combinatorial expression of different ephrinAs and EphAs, suggesting roles for ephrinA/EphA signaling in patterning thalamocortical projections (Sestan et al. 2001). In the olivocerebellar system, axons from the inferior olive project to Purkinje cells of the cerebellum in rostrocaudal and mediolateral patterns. Retroviral overexpression of ephrinA2 and truncated EphA3 disrupted the olivocerebellar map, suggesting a role for ephrinA/EphA signaling in guidance of inferior olive axons to their correct targets in the cerebellum (Nishida et al. 2002).

Motor neuron innervation of limb muscles is also positionally selective and in part regulated by ephrinA/ EphA interactions (for review, see Feng et al. 2000; Klein 2001). There is a topographically organized projection between motor neuron cell bodies within the lateral motor column (LMC) of the spinal cord and their targets within dorsal or ventral muscles. Motor neurons of the medial LMC innervate ventral muscles, whereas neurons in the lateral LMC innervate dorsal muscles. EphA4 is expressed by lateral LMC neurons, which innervate a target that expresses low levels of ephrinA. Conversely, medial LMC neurons do not express EphA4 and project to limb targets expressing high levels of ephrinA (Helmbacher et al. 2000; Eberhart et al. 2002 and references within). Loss of EphA4 can result in loss of innervation of muscles in the dorsal hindlimb, because axons are misguided to the ventral part of the limb (Helmbacher et al. 2000), consistent with repellent interaction with ephrinA ligands. Targeted misexpression of EphA4 in medial 
LMC neurons misroutes a majority of axon projections into dorsal limb (Eberhart et al. 2002). The precise mechanism of EphA-mediated dorsoventral guidance is, however, not yet resolved. EphrinA ligands are expressed not only by ventral limb mesoderm but also on motor axons, and both EphA4 and EphA7 are expressed in the dorsal part of the limb (Araujo et al. 1998; Helmbacher et al. 2000). Thus, ephrinA/EphA4-mediated pathway selection may involve both axon-axon and axon-mesoderm interactions (Eberhart et al. 2002).

\section{Axon guidance at the midline}

The central nervous system midline serves as an intermediate target for pathfinding axons, and many of the mechanisms that guide axons at the midline are conserved in bilaterally symmetric animals. The midline is the source of long-range and short-range attractants such as netrins and cell adhesion molecules, which attract commissural axons and allow them to cross to the contralateral side. But the midline also expresses repellent proteins such as Slits, which prevent recrossing of commissural axons and regulate axonal positions in contralateral longitudinal tracts (Guthrie 2001; for review, see Kaprielian et al. 2001). The ephrin-Eph system is critically involved in midline axon guidance. At least three mechanisms of Eph/ephrin action can be distinguished, involving both forward and reverse signaling (Fig. 4). First, ephrinB ligands expressed by midline cells are selective repellents for subsets of axons and thereby prevent them from crossing the midline. Second, ephrinB ligands define the position of longitudinally projecting commissural axons after they have crossed the midline. Third, ephrinB ligands expressed on commissural axons may act as signaling-competent guidance receptors.

To establish binocular vision, RGC axons from both eyes need to converge on the same area of the brain target. Whereas in all species, most RGC axons project to the contralateral side of the brain, in species with binocular vision, a fraction of RGC axons project ipsilaterally. These axons are guided ipsilaterally by diffusible and contact-dependent repellent guidance cues expressed by the critical midline choice point, the optic chiasm (Fig. 4A). During metamorphosis from the tadpole to the adult frog, the frog visual system undergoes major morphological changes including modifications in the projection pattern of retinal axons. Whereas all retinal axons project contralaterally in the early tadpole, newly generated RGCs send their axons ipsilaterally to the thalamus, thereby enabling binocular vision. Formation of ipsilateral projections coincides with the increased expression of ephrinB ligands, which act as repellents in the optic chiasm. Importantly, overexpression of ephrinB in the embryonic chiasm is sufficient to redirect EphB-expressing retinal axons to project ipsilaterally (Nakagawa et al. 2000). Although similar loss-offunction data are not yet available, these findings suggest a physiological role for ephrinB repellents in preventing subsets of retinal axons from crossing the midline.
A clear example of midline guidance by ephrinB repellents has been provided by genetic studies on the role of EphA4 and its ligand ephrinB3 during the formation of the corticospinal tract (CST; for review, see Kullander and Klein 2002). This fiber tract connects the brain with the spinal cord and provides central control over body movements. CST axons originate in the motor cortex and project to the brain-spinal-cord junction, where they cross the midline once before descending down in the contralateral side of the spinal cord, where they ultimately synapse with motor neurons (Fig. 4A). CST axons express EphA4, and ephrinB3 is expressed by spinal cord midline cells. In mice that carry alleles with noncatalytic mutants of EphA4 or a full deletion of ephrinB3, CST axons correctly cross the midline at the brain-spinal-cord junction, but aberrantly recross the spinal cord midline a second time (Kullander et al. 2001a,b; Yokoyama et al. 2001). These findings indicate a role for ephrinB3 in repelling EphA4-expressing CST axons at the level of the spinal cord. This morphological defect in mutant mice correlates with a striking rabbit-like hopping gait, part of which may be caused by aberrant CST axon projections. However, recent evidence indicates that EphA4 is also part of a local neuronal circuit that controls rhythmic walking. Local circuits in the spinal cord that generate locomotion are termed central pattern generators (CPGs). The CPGs present in isolated spinal cords from newborn rodents can be induced to display rhythmic left-right activity independent from brain input. Spinal cords from ephA4- and ephrinB3-null mice, however, display abnormal synchronous rhythm rather than the wild-type pattern of left-right alternation. The synchronous rhythm in the mutants could be reversed to left-right alternation by chemical strengthening of the inhibitory components of the CPG. Loss of ephrinB3EphA4 interactions caused aberrant midline crossings and therefore identified EphA4-positive neurons as an excitatory component of the locomotor CPG. It was suggested that midline ephrinB3 repels EphA4-positive neurons and restricts their connections to the ipsilateral side of the spinal cord (Kullander et al. 2003).

In contrast to their effects on corticospinal tract and CPG axons, midline ephrins do not appear to repel spinal cord commissural axons (Fig. 4B). EphB1 and EphA2 receptors were shown to be absent on ipsilateral axon segments and to be up-regulated on distal axon segments after midline crossing (Imondi et al. 2000; Brittis et al. 2002), providing an explanation for the lack of repulsion by midline ephrins. Interestingly, the mechanism for this up-regulation appears to involve localized protein translation and cell surface expression in the distal axon as shown for EphA2 (Brittis et al. 2002). After having crossed the midline, EphB-positive commissural axons are confronted with ephrinB repellents localized to the dorsal and intermediate spinal cord and to the floor plate. Perturbation of ephrinB-EphB interactions using Fc-fusion proteins during late phases of commissural axon pathfinding in the chick caused inappropriate projections into the ephrinB expression domains, suggesting that ephrinB ligands define the dorsoventral position at 


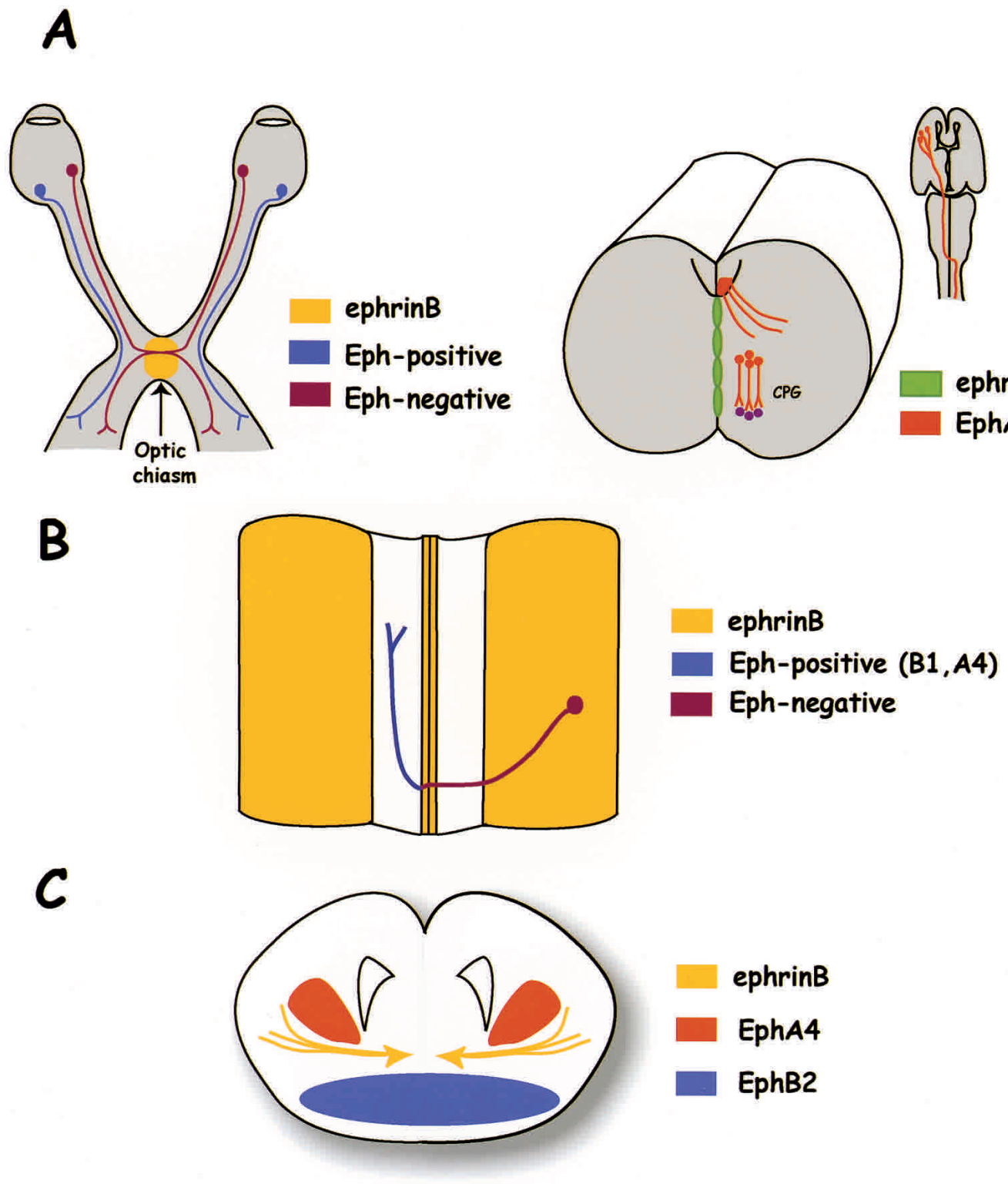

Figure 4. Axon guidance at the midline. $(A, l e f t)$ Midline ephrinB ligands repel subsets of Eph-expressing axons. In the frog visual system, ephrinB repellents are expressed in the optic chiasm, the major midline choice point for retinal axons extending from both eyes (left). Most retinal axons are Eph-negative and will cross to the contralateral side. The subset of retinal axons that expresses EphB receptors is repelled by the optic chiasm and directed to an ipsilateral pathway. (Right) EphA4-positive corticospinal tract axons (shown in red) originate in the motor cortex, travel to the brain-spinal cord junction, where they cross to the contralateral side and continue their path down the spinal cord (small cartoon depicting a mouse brain with neurons of the left hemisphere labeled). In the spinal cord (large cartoon, dorsal up, ventral down), CST axons are bundled in the dorsal funiculus, from where they extend branches into the ipsilateral spinal cord (in red). These EphA4-positive branches are repelled by ephrinB3-expressing midline cells (depicted in green). Other EphA4-positive neurons have their cell bodies within the spinal cord and represent part of the central pattern generator (CPG). These neurons, which are excitatory in nature, are also repelled by midline ephrinB3. (B) Schematic drawing of an "open book" preparation of an embryonic chick spinal cord (anterior up, posterior down) with ephrinB ligands expressed by the floor plate (in the middle) and by the dorsal to intermediate parts of the spinal cord (in yellow). Commissural neuron cell bodies are located in the dorsal spinal cord (in purple). Precrossing axons of commissural neurons are Eph-negative (in purple) and therefore do not respond to ephrins. Postcrossing distal axon segments up-regulate EphB1 and EphA2 expression (in blue) and are confined into a narrow longitudinal path by ephrinB ligands. $(C)$ Schematic drawing of a coronal section through an embryonic mouse forebrain (dorsal up, ventral down) at the level of the anterior commissure (shown in yellow). Commissural axons, which express ephrinB ligands, travel along territories rich in EphA4-positive (striatum, in red) and EphB2-positive (hypothalamus, in blue) cells. Ephrin-Eph interactions are critical for proper midline guidance of the AC axons. The fact that neither EphB2 nor EphA4 receptors require their catalytic activities to mediate this effect suggests that the ephrinB ligands are the signaling-competent partners in this process. 
which commissural axons turn into longitudinal tracts (Imondi and Kaprielian 2001).

Ephrin-Eph interactions also participate in the formation of commissural projections in the brain, such as the corpus callosum and the anterior and posterior commissures (for review, see Frisen et al. 1999). The formation of the anterior commissure $(\mathrm{AC})$ is particularly interesting, because AC axons express reverse signaling-competent ephrinB proteins, and AC formation in mice depends on the expression of EphB2 and EphA4 in territories through which $\mathrm{AC}$ axons migrate during their pathway across the midline (Fig. 4C). Defects in the anterior commissure are rescued in mice that carry catalytically inactive or Cterminally truncated versions of EphA4 or EphB2, respectively (Henkemeyer et al. 1996; Kullander et al. 2001b). These findings suggest that EphB2 and EphA4 act as nonsignaling partners for signaling-competent ephrinB proteins.

\section{Dendritic spine formation}

Spines are small thorn-like structures ("espinas"; Cajal 1888) on the surface of neuronal dendrites that receive excitatory synaptic input. They have attracted considerable attention because changes in their morphology are thought to correlate with synaptic plasticity and perhaps long-term memory (for review, see Bonhoeffer and Yuste 2002). Spines are remarkably dynamic in shape and size and may help the generation of synaptic connections by facilitating the initial contact with nearby axons. During development, dendrites grow long, thin protrusions, socalled filopodia, which later convert into more stubby, mushroom-shaped spines, coincident with formation of postsynaptic specializations. This transition is, however, reversible and regulated by local signals and neuronal activity (for review, see Hering and Sheng 2001). Knowledge of the molecular mechanisms regulating spine formation is still fragmentary, but research on this topic is very active. Prime candidates for the organization of the postsynaptic spine apparatus include PDZ-domain-containing scaffold proteins, such as PSD95 and Shank, which represent the molecular interface between cellsurface (neurotransmitter) receptors and the spine cytoskeleton (for review, see Hering and Sheng 2001).

Clustering of the cell-surface heparan-sulfate proteoglycan syndecan- 2 promotes spine maturation in cultured hippocampal neurons, an effect that required an intact $\mathrm{C}$ terminus including the PDZ target site (Ethell and Yamaguchi 1999). It was proposed that the C terminus of syndecan-2 recruited a protein complex that accelerated spine development. The same group has recently shown that postsynaptic EphB2, but not EphA receptors, phosphorylate syndecan-2 on cytoplasmic tyrosine residues and associate with syndecan- 2 in a phosphorylation-dependent manner (Ethell et al. 2001). Inhibition of EphB2 signaling by overexpression of a kinaseinactive EphB2 mutant blocked endogenous syndecan-2 clustering and spine formation. Likewise, a mutant syndecan-2 lacking critical tyrosine residues failed to induce spines in this assay (Fig. 5). Further genetic work will be required to investigate the role of EphB2 forward signaling in spine development and maintenance. Ultrastructural examination of synapse morphology has not revealed major changes in ephB2-null mutants, suggesting functional redundancy with other coexpressed Eph receptors (Grunwald et al. 2001; Henderson et al. 2001).

Downstream of Eph forward signaling, Rho-family GTPases have recently been implicated in spine morphogenesis. Treatment of hippocampal neurons with soluble ephrinB1-Fc induced the rapid formation of spine-like protrusions, an effect that was blocked by overexpression of a kinase-inactive EphB2 mutant. EphB2 tyrosine kinase phosphorylated the endogenous Rho-GEF kalirin in neurons, and ephrinB1 stimulation induced the redistribution of endogenous kalirin to larger and more synaptic clusters. By using additional dominantly interfering tools, the authors outlined a pathway from kalirin to filamentous actin formation and gene expression mediated by Rac1 and the p21-activated protein kinase Pak, a key target of Rac1 (Fig. 5; Penzes et al. 2003). These findings are consistent with data from Drosophila, in which genetic analysis demonstrated that Pak1 genetically interacts with Trio, the fly ortholog of kalirin, in a pathway through which Trio affects axon growth and guidance (Newsome et al. 2000). EphB2 also physically associates with the Rho-GEF intersectin and activates its GEF activity. Stimulation of neurons with ephrinB2-Fc led to an accumulation of activated Cdc42, but not Rac, and promoted spine morphogenesis (Fig. 5; Irie and Yamaguchi 2002).

Eph receptors have recently been shown to regulate dendritic spine morphology in hippocampal slices obtained from adult mice (Murai et al. 2003). Stimulation with ephrinA3-Fc followed by application of a lipophilic tracer post fixation showed a marked shortening of dendritic spines in the slices. This effect was not observed in slices obtained from ephA4 knockout mice and was much less pronounced after treatment of wild-type slices with ephrinB1-Fc. Comparison of wild-type with $e p h A 4^{-/-}$slices revealed that spines lacking EphA4 were irregular in shape and significantly longer than normal. Whereas the previous reports did not address the localization of ephrin ligands, Murai and coworkers found highest expression of ephrinA3 on astrocytic processes near synaptic terminals. This suggested that neuroglia interactions involving ephrinA3 and EphA4 forward signaling stabilize spine morphology and possibly synapses in the intact hippocampus (Murai et al. 2003). Although these findings are tantalizing, future work using conditional inactivation of ephrinA3 in astrocytes and of EphA4 in CA1 neurons will be required to test this model.

\section{Ephrins and synaptic plasticity}

The roles of ephrins and Ephs in the postnatal brain extend beyond neuron morphology to plasticity changes that are dependent on neuronal activity. Activity-dependent synaptic plasticity often requires $\mathrm{N}$-methyl-D-aspartate (NMDA)-type glutamate receptors, which con- 
Palmer and Klein

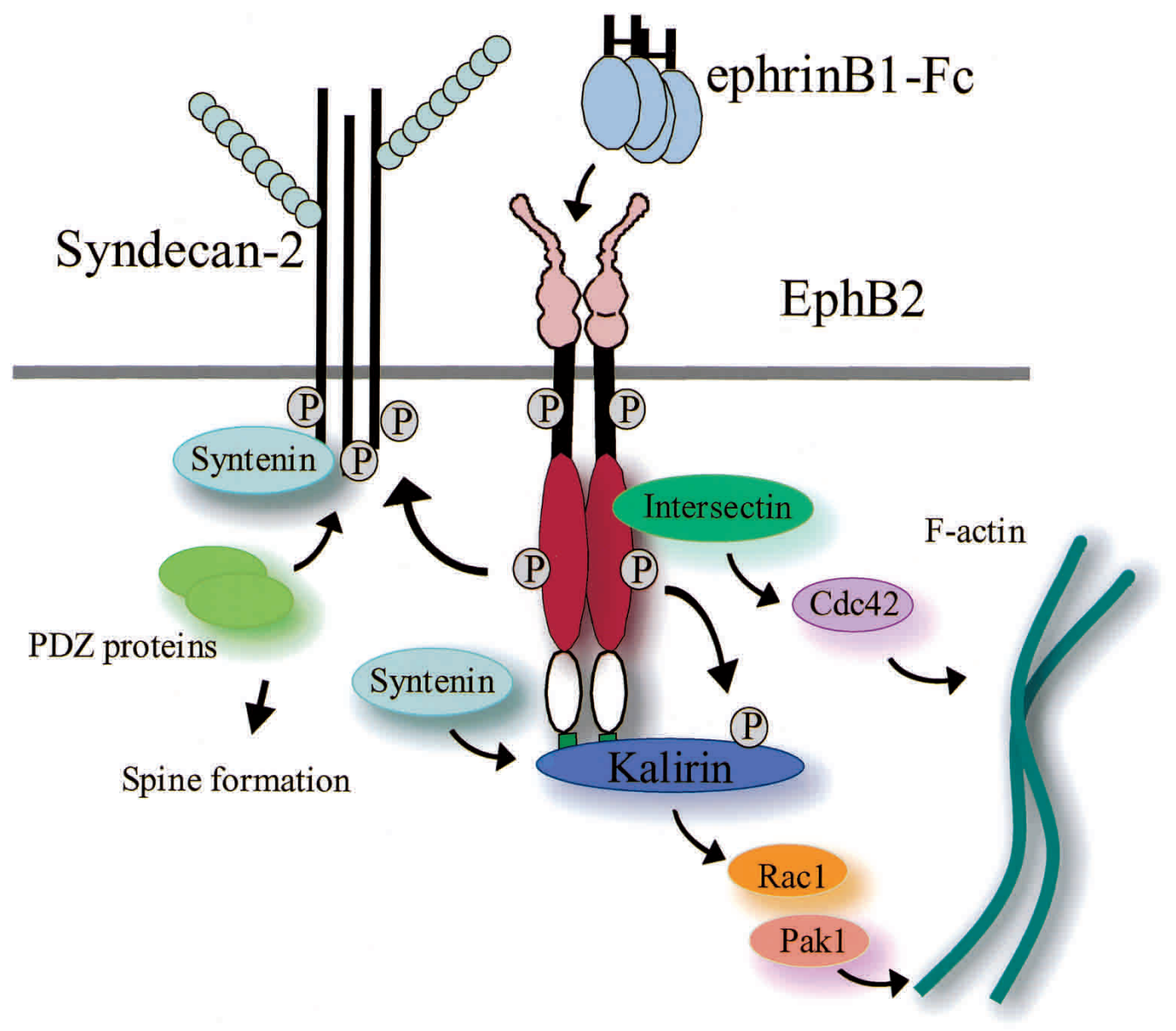

Spine formation

Figure 5. Signaling pathways regulating spine formation and turnover. Interaction between activated EphB2 receptors and the cell-surface proteoglycan syndecan-2 induces dendritic spine formation in hippocampal neurons. Syndecan-2 is found clustered at dendritic spines in mature neurons, and clustering of syndecan- 2 by activated EphB2 induces new spines. Clustering of syndecan- 2 is mediated by interaction with PDZ-domain-containing proteins, including syntenin, and by tyrosine phosphorylation of the syndecan- 2 cytoplasmic tail by EphB2. EphrinB1-Fc-induced spine formation in vitro also requires the interaction of EphB2 with kalirin and intersectin, Rho-GEF proteins enriched in spines. Activated EphB2 receptors phosphorylate endogenous kalirins and redistribute them to larger and more synaptic clusters. A GEF-inactive form of kalirin interfered with spine formation, as did dominant-negative forms of Racl. It appears as if Racl and p21-activated kinase Pak are key downstream mediators of ephrinB1-induced actin rearrangements in spine formation. Likewise, dominant-negative forms of intersectin inhibited spine formation in cultured neurons. Intersectin appears to promote spine formation by activating Cdc42 and not Rac1.

trol the entry of $\mathrm{Ca}^{2+}$ into the postsynaptic side of excitatory synapses. NMDA receptors are coincidence detectors, because they require both presynaptic activity (glutamate release) and postsynaptic activity (depolarization) for channel opening. $\mathrm{Ca}^{2+}$ influx by NMDA receptors and associated signaling pathways orchestrate synapse formation and plasticity (Helmchen 2002). EphB2 was shown to associate with and to induce clustering of NMDA receptors. This suggests that ephrinB ligands in synaptic membranes induce the maturation of glutamatergic synapses by promoting NMDA receptor aggregation (Fig. 6; Dalva et al. 2000). More recent data showed that in very young cultured neurons ephrinB1 stimulation enhanced NMDAR-mediated $\mathrm{Ca}^{2+}$ influx and potentiated phosphorylation of the transcription factor CREB and CREB-dependent transcriptional events (Grunwald et al. 2001; Takasu et al. 2002). This suggested a model in which ephrin-Eph signaling influences activity-dependent processes $\left(\mathrm{Ca}^{2+}\right.$ influx) by modulating gene expression during development of synaptic connections. Mechanistically, EphB2 receptor activation was shown to recruit and activate Src-family kinases, which then phosphorylate certain subunits of the NMDA receptor (Grunwald et al. 2001; Takasu et al. 2002). This posttranslational modification is required for EphB2-mediated enhancement of $\mathrm{Ca}^{2+}$ influx, at least in a transfected cell system (Takasu et al. 2002).

These in vitro observations are consistent with earlier reports on $e p h B 2$-deficient mice that showed a requirement for EphB2 in hippocampal long-term synaptic changes (Grunwald et al. 2001; Henderson et al. 2001; for review, see Murai and Pasquale 2002). Reduction or even 


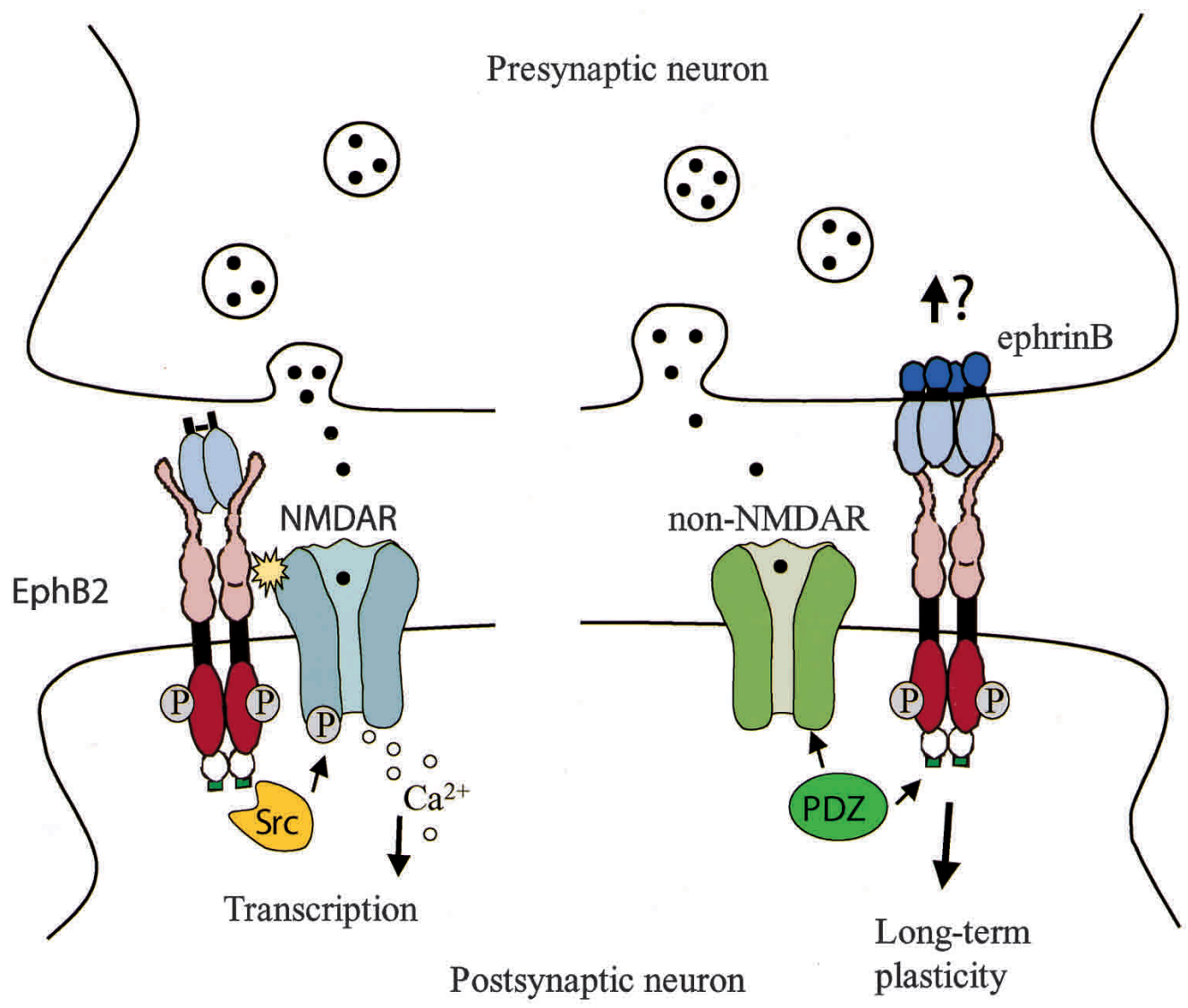

Figure 6. EphB2 receptor regulation of synaptic plasticity. (Left) Stimulation of immature cultured neurons with soluble ephrinB ligand causes interaction of EphB2 with NMDA-type glutamate receptors via their ectodomains (indicated by yellow flash). This interaction clusters NMDA receptors and enhances their potential to flux $\mathrm{Ca}^{2+}$ ions upon electrical stimulation. Ca ${ }^{2+}$ influx activates signaling pathways that ultimately result in transcriptional responses. An essential component of this model is the activation of EphB2 kinase activity, the recruitment of Src-family kinases, and the phosphorylation of NMDA receptors on tyrosine residues. The source of ephrinB has not been addressed. (Right) LTP at Mossy fiber synapses requires the interaction of EphB receptors with non-NMDAtype glutamate receptors via interaction with PDZ-domain proteins, such as glutamate-receptor-interacting-protein (GRIP). The role of EphB2 kinase signaling has not been addressed in this system. Also, the location of the ephrinB ligand in mossy fiber LTP has not been addressed. One testable hypothesis states that EphB2 binding of presynaptic ephrinB ligands may cause long-lasting changes in neurotransmitter release by ligand reverse signaling.

loss of hippocampal long-term potentiation and longterm depression correlated with a redistribution of a significant fraction of NMDA receptors as shown by cultured neurons and by immunogold labeling. However, because NMDA receptor currents were not significantly altered, it is not clear whether the altered plasticity in $e p h B 2$ mutants is entirely caused by changes in NMDA receptor activity. Targeted expression of a kinase-deficient EphB2 receptor isoform rescued the defects in ephB2-deficient mice, suggesting that ephrinB ligand reverse signaling may play role at the synapse (Grunwald et al. 2001; Henderson et al. 2001). Curiously, with respect to the Schaffer collateral pathway, ephrinB2 and ephrinB3 mRNA expression in the adult hippocampus is much higher in postsynaptic CA1 neurons than in presynaptic CA3 neurons (Grunwald et al. 2001; Liebl et al. 2003). This leaves open the possibility of postsynaptic ephrinB reverse signaling, an interesting mechanism that urgently needs to be addressed.
Recent data provided evidence for a role of ephrinBEphB interactions in non-NMDA-receptor-dependent forms of synaptic plasticity (Contractor et al. 2002). LTP at the so-called Mossy fiber synapse is dependent on receptors of the non-NMDA subclass and requires longlasting changes in presynaptic neurotransmitter (glutamate) release (Mellor and Nicoll 2001). Induction of this form of LTP has now been proposed to involve a new mechanism: Postsynaptic activation of non-NMDA-type glutamate receptors occurs by electrical stimulation and is followed by interaction with and clustering of postsynaptic EphB receptors via PDZ-domain interactions (Fig. 6; Contractor et al. 2002). Blockage of EphB2-PDZ interactions by infusion into CA3 pyramidal neurons of a C-terminal peptide including the PDZ target site of EphB2 (but not of a similar peptide including the PDZ target site of EphA7) impaired Mossy fiber LTP. Similar results were obtained with an antibody directed against the $\mathrm{C}$ terminus of EphB2. Clustering of EphB2 via PDZ 
interactions was proposed to activate reverse signaling by ephrinB ligands (Contractor et al. 2002), which are indeed highly expressed by presynaptic dentate gyrus neurons (Grunwald et al. 2001; Liebl et al. 2003). The validity of this model still requires additional genetics. Likewise, the role of EphA receptors, in particular of EphA4, needs to be addressed genetically, because biochemical inhibition of ephrinA-EphA interactions in the adult brain caused significant impairments in neuronal plasticity and behavior (Gerlai 2001 and references therein).

\section{Neurogenesis and regeneration}

\section{Neurogenesis}

In early phases of development, primary neurogenesis takes place in the compact germinal zones lining the ventricles, the so-called ventricular zone (VZ). This layer of highly proliferative cells contains the progenitors of all neurons and macroglial cells. Differentiation of progenitors requires a switch from proliferative divisions to neuron-generating divisions. Eph/ephrins are localized in the proliferative ventricular zone of the embryonic cortex (Stuckmann et al. 2001). In a search to identify molecules involved in neurogenesis, ephrinB1 was found to be highly expressed in the neuroephithelium of the developing telencephalon, and the onset of its expression correlated with the onset of neurogenesis. Functional evidence for a role of ephrinB1 in primary neurogenesis is still lacking.

Secondary neurogenesis takes place in a specialized germinal matrix that arises in higher vertebrates to generate neuronal cell populations during late development of the CNS. This layer of mitotically active cells, situated just above the $\mathrm{VZ}$, is called the subventricular zone (SVZ). In humans, secondary neurogenesis continues into early childhood through the second year of life. During this period, neurogenesis in the SVZ of the forebrain and in the EGL of the cerebellum supplies the corresponding brain structures (hippocampus and granule cells of the IGL) with large numbers of neurons. In the forebrain, cells from the SVZ will give rise to neurons that migrate into the olfactory bulbs, to cortical glial cells, and to the granule cell population of the hippocampal formation. Eph receptors and ephrins have been localized to the SVZ, and disruption of Eph/ephrin signaling by intraventricular infusion of truncated soluble Eph-Fc or ephrin-Fc fusion proteins into the SVZ of adult mouse brain results in disorganized migration patterns and increased cell proliferation (Conover et al. 2000). EphA4, EphB1, and EphB2 are expressed in the SVZ and along the migratory pathway and might be involved in guidance of neuroblasts or in organization of migrating neuroblasts into chains. There are two possibilities to explain the increased proliferation of astrocytes. Either Eph/ephrin signaling regulates cell proliferation directly, suggesting a new role for these molecules in eliciting a mitogenic response, or indirectly by allowing movement of astrocytes to the ventricle surface. In support of this second possibility, SVZ astrocyte invasion of the ependymal layer has been suggested to be necessary to trigger stem cell activation and proliferation (Doetsch et al. 1999|, and infusion of EphB2-Fc resulted in many astrocytes contacting the ventricle surface.

\section{Neuroregeneration}

The adult CNS of mammals possesses little ability for self-repair after injury because of different inhibitory processes (for review, see Goldberg and Barres 2000). At present, various approaches aim to overcome such obstacles to achieve regeneration of axons after injury as well as correct reinnervations of their target tissues. It is generally believed that molecules involved in axon guidance during embryonic development could be reused in the adult after lesioning axon tracts to re-establish the functional integrity of neuronal circuits (Aubert et al. 1995). Up-regulation of Eph receptor expression is observed following injury to the adult spinal cord (Miranda et al. 1999), hippocampus (Moreno-Flores and Wandosell 1999), and cochlear nucleus (Pickles and van Heumen 1997). In lower vertebrates, such as fish and amphibians, retinal ganglion cells (RGCs) are newly formed throughout life, and retinal axons continuously regrow into the tectum. In these species, the optic nerve is capable of extensive regeneration after lesion. Expression of ephrinA molecules was shown in the adult and regenerating goldfish and zebrafish tectum (Becker et al. 2000; Rodger et al. 2000). A transient up-regulation of the rostrocaudal gradient of ephrinA2 in the tectum coincides with reestablishment of projections during optic nerve regeneration in goldfish (Rodger et al. 2000). Likewise, ephrinA2 was up-regulated in the superior colliculus (SC) of neonatal rats following brachial section (Symonds et al. 2001) and in adult rat following unilateral optic nerve section (Rodger et al. 2001). Knoll et al. (2001a) demonstrated a graded expression pattern of ephrinA in the SC of mice before and after lesion of the optic nerve, remarkably similar to the expression patterns found during development, suggesting that topographic guidance information for a successful re-establishment of the retinocollicular projection was available. Interestingly, RGC axons do not exert guidance preferences in response to membranes from adult unlesioned SC, but only in response to membranes from deafferented SC (Wizenmann et al. 1993; Bahr and Wizenmann 1996). In normal adult tissue, the repellent activity of ephrinA is blocked by coexpression of EphA receptors in the SC, such that EphA receptors on retinal axons cannot bind the ephrins in the SC membranes. EphA receptor expression is severely reduced in the SC after lesion, and therefore the guidance of function of ephrinA ligands might be reactivated (Knoll et al. 2001a).

\section{Vascular development}

In the embryo, blood vessels form through two distinct processes, vasculogenesis and angiogenesis. Vasculogen- 
esis involves the de novo differentiation of endothelial cells from mesodermal precursors, whereas in angiogenesis new vessels are generated from pre-existing ones. Vasculogenesis takes place only during embryonic development and leads to the formation of a primary vascular plexus, followed by angiogenesis stages during which this early vasculature undergoes remodeling and maturation (Risau 1997). In vivo evidence that members of the Eph-ephrin family are involved in the development of the vasculature came from studies in mouse embryos bearing targeted null mutations in the genes for EphB4 (Gerety et al. 1999) and ephrinB2 (Wang et al. 1998; Adams et al. 1999; for review, see Cheng et al. 2002a). These mice showed defects in early angiogenic remodeling that led to embryonic lethality around E10.0. Moreover, these studies revealed an interesting reciprocal expression pattern within the developing vasculature, in which ephrinB2 is expressed in the endothelium of primordial arterial vessels, whereas EphB4 expression marks the endothelium of primordial venous vessels. These observations suggest the involvement of ephrinB2 and EphB4 in establishing arterial versus venous identity in the developing embryo. Removal of the cytoplasmic domain of ephrinB2 caused a severe phenotype with defects in angiogenic remodeling and vasculogenesis. This phenotype strongly resembled the ephrinB2-null phenotype (Adams et al. 2001) and suggested a requirement of ephrinB2 reverse signaling for vascular remodeling. Further genetic studies are required to address whether both reverse and forward signaling are required for the development of the vasculature.

\section{Nerve/blood vessel interactions}

It has been known for more than a decade that peripheral nerves associate with subsets of blood vessels (Martin and Lewis 1989), but the significance of this association was not clear. A recent study from Mukouyama et al. (2002) has shed light into how and to what extent the nervous system influences blood vessel patterning. Using genetic tools to eliminate or disorganize peripheral nerves in the embryonic mouse limb skin, it was shown that sensory nerves determine the pattern of arterial differentiation and blood vessel branching. Arteries are preferentially aligned with nerves and follow their branching pattern, whereas veins are not. In mutant embryos lacking sensory nerves, arteries fail to properly differentiate, whereas in those embryos containing disorganized nerves, the trajectory of blood vessel branching was altered to follow the nerve. The data presented in this study also suggest that the expression of arterial markers in nerve-associated vessels may be controlled by local secretion of VEGF from sensory nerve fibers, from Schwann cells, or from both (Mukouyama et al. 2002). It is intriguing that VEGF, representing a general angiogenic factor, is only capable of inducing ephrinB2 expression in arteries and not in veins, suggesting a permissive rather than an instructive role for VEGF in determining arterial identity.

\section{Mesenchyme/endothelium interactions}

Other ephrins and Ephs are coexpressed on both arteries and veins and on the mesenchyme surrounding blood vessels, suggesting a complicated scenario of Eph/ephrin interaction between arteries, veins, and mesenchymal cells (for review, see Adams 2002). Studies in mouse (Adams et al. 1999) and Xenopus (Helbling et al. 2000) attributed a role for mesenchyme-derived ephrinB2 signals in restricting blood vessel growth to the intersomitic space. Gerety and Anderson (2002) have used a conditional gene-targeting strategy to ask if ephrinB2 derived from perivascular mesenchyme is sufficient to drive vascular remodeling by specifically removing ephrinB2 from endothelial cells. The endothelial-specific knockout of ephrinB2 leads to angiogenic remodeling and cardiac defects that are indistinguishable from those of the conventional ephrinB2 knockout. Therefore, ephrinB2 is required specifically in the endothelial and endocardial cells for angiogenesis. Generation of mesenchyme-specific Cre transgenic mice will be necessary to address the mesenchymal requirement for ephrinB2 in angiogenesis.

\section{Postnatal and tumor angiogenesis}

\section{Postnatal angiogenesis}

The early death of embryos lacking ephrinB2 or EphB4 did not permit the functional analysis of these molecules in postnatal life. The previous studies raised the question whether the identity distinctions between arteries and veins required to assemble the circulatory system must be maintained once development is complete. Furthermore, the potential requirement for ephrinB2 in adult normal and pathological angiogenesis remained poorly understood. Gale et al. (2001) and Shin et al. (2001) addressed these questions by generating engineered mice in which lac $Z$ replaced the ephrinB2 coding region, allowing the characterization of ephrinB2 distribution as development proceeds and in the adulthood. EphrinB2 continues to selectively mark arteries during later embryonic development as well as in the adult, where it extends into some of the smallest-diameter microvessels. These observations challenge the classically held view that capillaries have neither arterial nor venous identity. Moreover, expression of ephrinB2 in the adult extended progressively to the smooth muscles cells surrounding the vessels, suggesting a role in smooth muscle layer assembly.

\section{Angiogenesis in cancer}

The process of neovascularization is essential for solid tumors to assure their survival and growth. Several studies indicate that Eph receptors and ephrins are up-regulated as blood vessels invade tumors. Both forward and reverse signaling by the EphB/ephrinB system has been shown to induce endothelial cells in vitro to replicate various aspects of angiogenesis, including vessel formation and sprouting (Adams et al. 2001; Palmer et al. 2002; 
Füller et al. 2003; Fig. 7A). Phosphorylation of the cytoplasmic tail of ephrinB ligands by Src family kinases is required for such angiogenic induction (Palmer et al. 2002). It is particularly interesting that in adult settings of angiogenesis, such as tumors and the female reproductive system, the arterial marker ephrinB2 is highly expressed by the endothelium of some angiogenic vessels and their sprouts, showing an arterial identity for these microvessels and contravening the classically held view that tumor vessels arise exclusively from postcapillary venules (Gale et al. 2001; Shin et al. 2001). Additional recent work in the field has focused the attention on EphA2 and its ligand ephrinA1. EphA2 is exclusively expressed in sites of neovascularization in the adult and

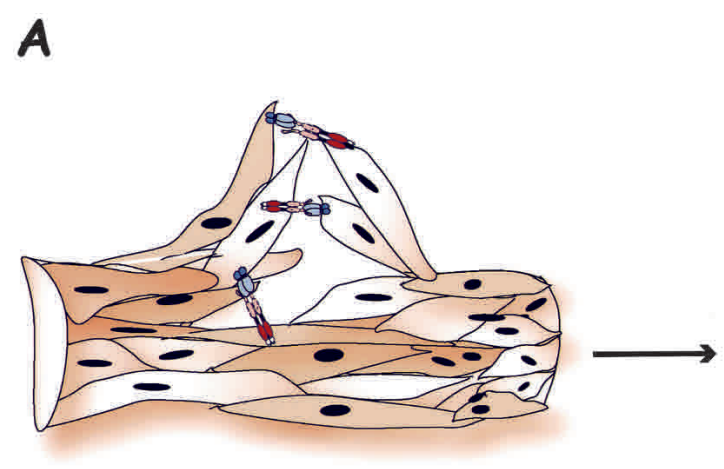

Deadhesion, Mobility, Migration

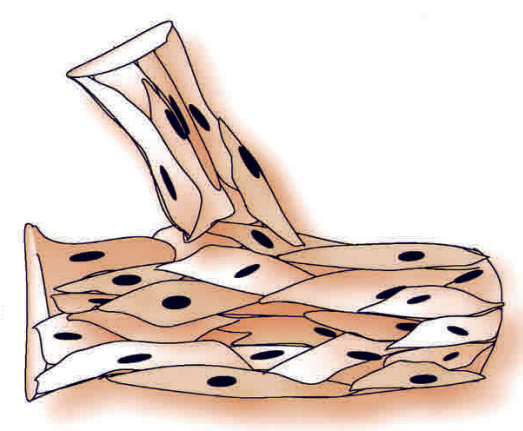

Sprouting

\section{B}
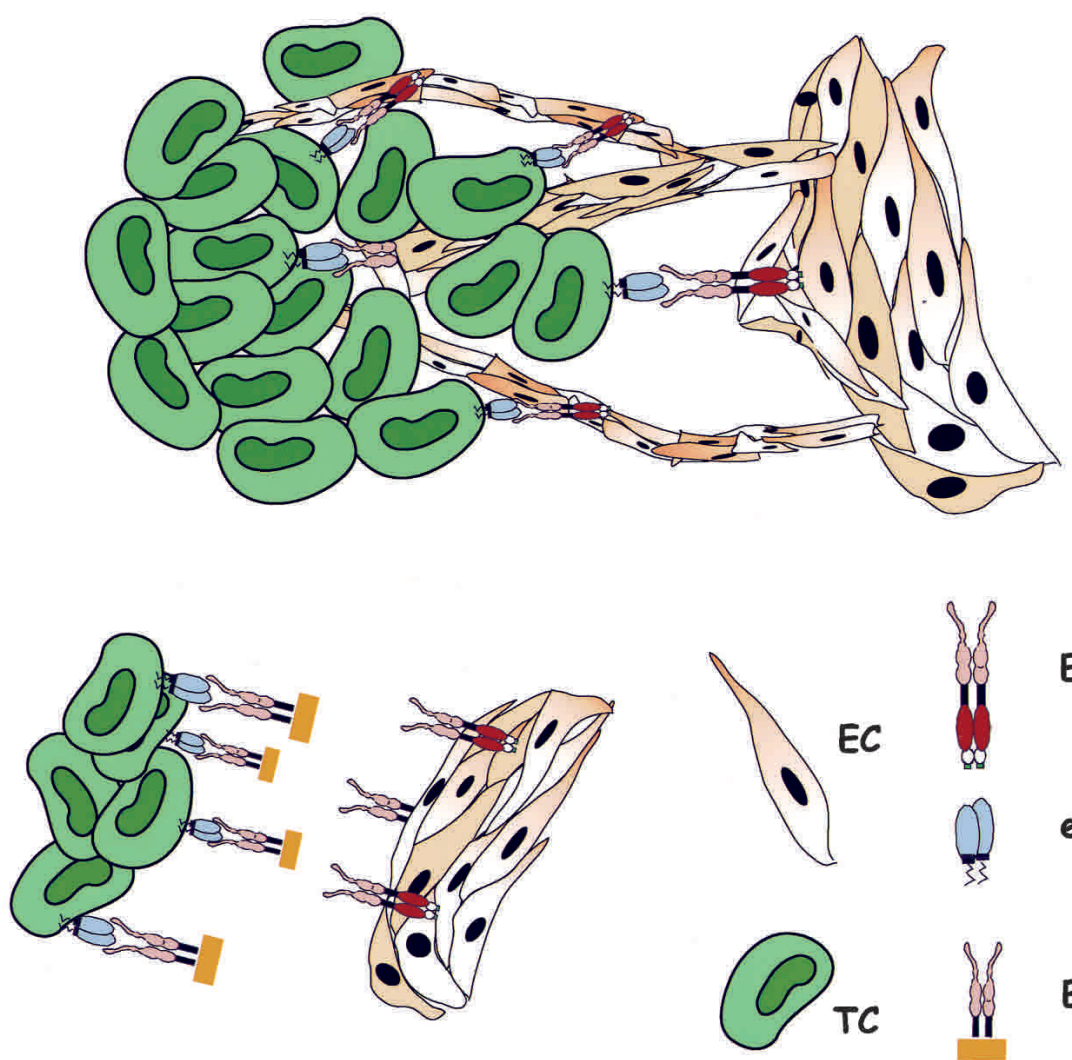

EphA2

ephrinA1

EphA2-Fc

Figure 7. Eph/ephrin signaling functions during angiogenesis. (A) Eph/ephrin bidirectional signaling in endothelial cells (EC). Ephrins expressed in ECs interact with Eph receptors on adjacent ECs, and repulsive forces promote deadhesion, mobility, and migration of these cells, resulting in sprouting of new vessels from pre-existing ones. (B) Proposed mechanism for EphA2/ephrinA1 signaling in the regulation of pathogenic angiogenesis in tumors. EphrinA1 is expressed predominantly in tumor cells (TC), and EphA2 expression is mainly associated with tumor vasculature. EphrinAl expressed on tumors cells might induce the sprouting and guide the incoming vessels expressing EphA2 by direct binding to the receptor in these vessels (situation represented in the drawing). Soluble EphA2-Fc inhibits tumor angiogenesis and tumor growth in vivo most likely by interfering with the binding of ephrinAl in tumor cells with the endogenous receptors in the vessels. 
has not been detected in either embryonic or quiescent adult blood vessels. In a human tumor xenograft model in nude mice, EphA2 and ephrinA1 were coexpressed in xenografted endothelial cells and in tumor cells, as well as in surgically removed human tumors. Functionally, a requirement for EphA2 signaling was shown in vitro by blocking capillary tube-like formation by human umbilical vein endothelial cells with a dominant negative form of EphA2 (Ogawa et al. 2000).

The complementary expression of ephrinA1 in tumor cells and EphA2 in tumor-associated blood vessel endothelium was recently confirmed (Brantley et al. 2002). These authors provided the first functional evidence for EphA class receptor regulation of pathogenic angiogenesis in tumors. Treatment with soluble EphA2-Fc chimeric receptors in a vascular window assay resulted in decreased neovascularization in two different tumor models and in impaired tumor progression in vivo (Fig. 7B). In culture, EphA2-Fc had no effect on tumor cell proliferation and apoptosis. However, this treatment inhibited endothelial cell migration in response to tumor cells in a transwell coculture assay, suggesting a direct effect on tumor angiogenesis without affecting proliferation or apoptosis of the tumor itself. A cooperative model of ephrinA/EphA-mediated tumor angiogenesis in the context of VEGF signaling has been proposed based on the ability of EphA2-Fc to inhibit many of the angiogenic activities of VEGF. In fact, another study from the same authors (Cheng et al. 2002b) shows ephrinA1 as a downstream target gene induced by VEGF. Blocking EphA receptor activation inhibits specifically VEGF-dependent endothelial cell migration, sprouting, and survival in vitro and angiogenesis in vivo. Pratt and Kinch (2002) have now provided a mechanism by which EphA2 could negatively regulate extacellular matrix attachments. EphA2 interacts in an activation-dependent manner with the Shc adaptor protein, which in turn recruits Grb2. Ligand stimulation of EphA2 promotes the nuclear translocation and phosphorylation of ERK kinases, followed by an increase in nuclear induction of the Elk-1 transcription factor (Pratt and Kinch 2002). However, in another study, ephrinAl stimulation was shown to suppress ERK/MAPK activity and proliferation of immortalized prostatic epithelial cells and primary prostatic cancer cells (Miao et al. 2001). Furthermore, VEGF-induced activation of the ERK/MAPK pathway was reduced after stimulation with ephrinAl. Therefore, contradictory results concerning the inhibition or activation of MAPK downstream of EphA2 make it difficult to draw conclusions about the molecular mechanisms of the cross-talk between Eph receptors and other receptors like VEGFR. Indeed, activation of EphB kinases by ephrinB2 in venous endothelial cells also suppresses the VEGF- and angiopoietin-1-induced Ras/ MAPK pathway (Kim et al. 2002) and VEGF-induced sprouting (Füller et al. 2003). From this and other studies, the most consistent model suggests that activation of Eph receptors suppresses MAPK activity as part of a general mechanism to negatively regulate other RTK signaling.

\section{Ephrins in tumorigenesis}

Several Eph receptors and ephrins have been shown to be up-regulated in tumors, particularly during the more invasive stages of tumor progression (for review, see Dodelet and Pasquale 2000; Nakamoto and Bergemann 2002; Cheng et al. 2002a). The demonstration of Eph and ephrins playing a causal role in tumorigenesis or cancer progression is still questionable. Nevertheless, in recent years and based on preliminary studies, the idea that Eph receptors and their ligands could constitute useful targets for cancer therapy treatment became an issue for discussion. EphA2 is up-regulated in many tumors, and its highest levels are found on the most aggressive tumor cells. Interestingly, EphA2 overexpression is sufficient to confer malignant transformation and tumorigenic potential on nontransformed mammary epithelial cells (Zelinski et al. 2001). Overexpression of EphA2 did not affect proliferation of the cells but, rather, changed their behavior in three-dimensional assays like invasion in matrigels. The present model implies that in normal epithelial cells, low levels of EphA2 are all bound to ephrinA1 in sites of cell-to-cell contact. The biological effects of ligand binding include decreased extracellular matrix (ECM) attachments, decreased cell migration, and inhibition of malignant growth (Zantek et al. 1999; Miao et al. 2000, 2001; Zelinski et al. 2001). In contrast, malignant cells express high levels of EphA2, which is mislocalized in the cell and is not able to bind endogenous ligands and therefore is not activated by tyrosine phosphorylation. This results in an increase of ECM adhesions, a typical feature of metastatic cells that have gained access to the circulation and that are responsible for the formation of tumor colonies at distant sites (Ruoslahti 1999; Zantek et al. 1999; Zelinski et al. 2001). Thus, EphA2 may function during metastasis in a fashion that is independent of, as well as inhibited by, autophosphorylation of the receptor. Miao et al. (2000) showed that EphA2 receptor interacts with focal adhesion kinase and stimulation with the ligands reduces FAK phosphorylation and FAK activity, resulting in inhibition of integrin-mediated cell adhesion. Mislocalization and hyperactivation of FAK, because of its constitutive binding to EphA2, in metastatic cells could result in the increase of ECM attachments. Therefore, it appears that the EphA2 receptor could potentially constitute an effective novel target for therapeutic intervention in diseases associated to pathogenic angiogenesis. Toward that end, efforts have been directed to generate monoclonal antibodies that mimic the actions of ephrinA1 and therefore could have the potential to reverse metastatic behavior by activating the high levels of EphA2 on a tumor cell surface (Carles-Kinch et al. 2002). Also, Koolpe et al. (2002) have identified two peptides that target the ligand-binding domain of EphA2 and compete with ephrin ligands for binding. One of these peptides shows bioactive properties in that it stimulates EphA2 tyrosine phosphorylation and signaling and can deliver phage particles to endothelial and tumor cells expressing EphA2. This could be a potential strategy to 
deliver agents and modify EphA2 signaling in the receptor-expressing tumors (Koolpe et al. 2002).

As discussed previously, the Wnt pathway determines cell positioning in the small intestine along the crypt axis by controlling the expression of EphB and ephrinB genes (Batlle et al. 2002; van de Wetering et al. 2002). In colorectal cancer $(\mathrm{CRC})$, nuclear $\beta$-catenin accumulates in a cell-autonomous fashion as a result of the mutational activation of the Wnt pathway. Polyps in min (multiple intestinal neoplasia) mice develop as invaginations of the epithelial layer and express high levels of EphB2 and EphB3. The observation that the initial polyp outpocketing arises at the crypt-villus junction, where the mutant cells overexpressing EphB receptors encounter the maximum threshold of ephrin-mediated repulsion, supports the role of Eph/ephrin system in the formation of polyps in CRC. The investigators speculate that the initial founding polyp cells, expressing high levels of EphB receptors, migrate abnormally inside the villus to avoid the area of high ephrinB expression at the top of the crypt. Direct proof for the involvement of EphB receptors in CRC will have to await genetic experiments with Eph-deficient mice.

\section{Future perspectives}

Eph receptors and ephrin ligands mediate cell-cell interaction in many important biological processes. Initially, most efforts were focused on elucidating Eph-ephrin functions during embryonic development of the nervous and vascular systems. More studies have underscored that ephrins are involved in many morphogenetic processes, and that their functions are conserved among the different phyla. Accumulating evidence also points to important roles in remodeling adult tissues. Many members of the Eph and ephrin families are expressed in cell types that undergo plastic reorganization in adult organs, suggesting a general role for these molecules in directing migration and positioning of cells in a wide variety of tissues. The involvement in long-term changes of neuronal plasticity is particularly interesting. However, the cellular and molecular mechanisms are far from understood. Adult functions of ephrins include pathological processes like neovascularization of tumors and raises the possibility that these molecules will become candidates for tumor prognostic markers and potential targets for therapeutic intervention in cancer. Clearly, the challenge is now to understand which molecular mechanisms govern the functions of Eph-ephrins in these pathological processes. Undoubtedly, our knowledge on how these molecules work during embryogenesis is going to be very valuable for the analysis of Eph-ephrins in disease states.

\section{Acknowledgments}

We thank F. Helmbacher, I.C. Grunwald, G.A. Wilkinson, and M. Zimmer for critically reading the manuscript. Work in the laboratory was supported by grants from the Human Frontiers
Science Programme Organization, the Deutsche Forschungsgemeinschaft, and the Max-Planck Society.

\section{References}

Adams, R.H. 2002. Vascular patterning by Eph receptor tyrosine kinases and ephrins. Semin. Cell Dev. Biol. 13: 55-60.

Adams, R.H., Wilkinson, G.A., Weiss, C., Diella, F., Gale, N.W., Deutsch, U., Risau, W., and Klein, R. 1999. Roles of ephrinB ligands and EphB receptors in cardiovascular development: Demarcation of arterial/venous domains, vascular morphogenesis and sprouting angiogenesis. Genes \& Dev. 13: 295306.

Adams, R.H., Diella, F., Hennig, S., Helmbacher, F., Deutsch, U., and Klein, R. 2001. The cytoplasmic domain of the ligand ephrinB2 is required for vascular morphogenesis but not cranial neural crest migration. Cell 104: 57-69.

Araujo, M., Piedra, M.E., Herrera, M.T., Ros, M.A., and Nieto, M.A. 1998. The expression and regulation of chick EphA7 suggests roles in limb patterning and innervation. Development 125: 4195-4204.

Aubert, I., Ridet, J.L., and Gage, F.H. 1995. Regeneration in the adult mammalian CNS: Guided by development. Curr. Opin. Neurobiol. 5: 625-635.

Bahr, M. and Wizenmann, A. 1996. Retinal ganglion cell axons recognize specific guidance cues present in the deafferented adult rat superior colliculus. J. Neurosci. 16: 5106-5116.

Batlle, E., Henderson, J.T., Beghtel, H., van den Born, M.M., Sancho, E., Huls, G., Meeldijk, J., Robertson, J., van de Wetering, M., Pawson, T., et al. 2002. $\beta$-Catenin and TCF mediate cell positioning in the intestinal epithelium by controlling the expression of EphB/ephrinB. Cell 111: 251-263.

Becker, C.G., Meyer, R.L., and Becker, T. 2000. Gradients of ephrin-A2 and ephrin-A5b mRNA during retinotopic regeneration of the optic projection in adult zebrafish. J. Comp. Neurol. 427: 469-483.

Bonhoeffer, T. and Yuste, R. 2002. Spine motility. Phenomenology, mechanisms, and function. Neuron 35: 1019-1027.

Brantley, D.M., Cheng, N., Thompson, E.J., Lin, Q., Brekken, R.A., Thorpe, P.E., Muraoka, R.S., Cerretti, D.P., Pozzi, A., Jackson, D., et al. 2002. Soluble Eph A receptors inhibit tumor angiogenesis and progression in vivo. Oncogene 21: 7011-7026.

Brittan, M. and Wright, N.A. 2002. Gastrointestinal stem cells. J. Pathol. 197: 492-509.

Brittis, P.A., Lu, Q., and Flanagan, J.G. 2002. Axonal protein synthesis provides a mechanism for localized regulation at an intermediate target. Cell 110: 223-235.

Brown, A., Yates, P.A., Burrola, P., Ortuno, D., Vaidya, A., Jessell, T.M., Pfaff, S.L., O'Leary, D.D., and Lemke, G. 2000. Topographic mapping from the retina to the midbrain is controlled by relative but not absolute levels of EphA receptor signaling. Cell 102: 77-88.

Cajal, R.y. 1888. Estructura de los centros nerviosos de las aves. Rev. Trim. Histol. Norm. Pat. 1: 1-10.

Carles-Kinch, K., Kilpatrick, K.E., Stewart, J.C., and Kinch, M.S. 2002. Antibody targeting of the EphA2 tyrosine kinase inhibits malignant cell behavior. Cancer Res. 62: 2840-2847.

Chan, J., Mably, J.D., Serluca, F.C., Chen, J.N., Goldstein, N.B., Thomas, M.C., Cleary, J.A., Brennan, C., Fishman, M.C., and Roberts, T.M. 2001. Morphogenesis of prechordal plate and notochord requires intact Eph/ephrin B signaling. Dev. Biol. 234: 470-482.

Cheng, N., Brantley, D.M., and Chen, J. 2002a. The ephrins and Eph receptors in angiogenesis. Cytokine Growth Factor Rev. 
13: $75-85$.

Cheng, N., Brantley, D.M., Liu, H., Lin, Q., Enriquez, M., Gale, N., Yancopoulos, G., Cerretti, D.P., Daniel, T.O., and Chen, J. 2002b. Blockade of EphA receptor tyrosine kinase activation inhibits vascular endothelial cell growth factor-induced angiogenesis. Mol. Cancer Res. 1: 2-11.

Chin-Sang, I.D., George, S.E., Ding, M., Moseley, S.L., Lynch, A.S., and Chisholm, A.D. 1999. The ephrin VAB-2/EFN-1 functions in neuronal signaling to regulate epidermal morphogenesis in C. elegans. Cell 99: 781-790.

Chin-Sang, I.D., Moseley, S.L., Ding, M., Harrington, R.J., George, S.E., and Chisholm, A.D. 2002. The divergent C. elegans ephrin EFN-4 functions in embryonic morphogenesis in a pathway independent of the VAB-1 Eph receptor. Development 129: 5499-5510.

Conover, J.C., Doetsch, F., Garcia-Verdugo, J.M., Gale, N.W., Yancopoulos, G.D., and Alvarez-Buylla, A. 2000. Disruption of Eph/ephrin signaling affects migration and proliferation in the adult subventricular zone. Nat. Neurosci. 3: 1091-1097.

Contractor, A., Rogers, C., Maron, C., Henkemeyer, M., Swanson, G.T., and Heinemann, S.F. 2002. Trans-synaptic Eph receptor-ephrin signaling in hippocampal mossy fiber LTP. Science 296: 1864-1869.

Cooke, J.E. and Moens, C.B. 2002. Boundary formation in the hindbrain: Eph only it were simple. Trends Neurosci. 25: 260-267.

Cooke, J., Moens, C., Roth, L., Durbin, L., Shiomi, K., Brennan, C., Kimmel, C., Wilson, S., and Holder, N. 2001. Eph signalling functions downstream of $\mathrm{Val}$ to regulate cell sorting and boundary formation in the caudal hindbrain. Development 128: $571-580$.

Dalva, M.B., Takasu, M.A., Lin, M.Z., Shamah, S.M., Hu, L., Gale, N.W., and Greenberg, M.E. 2000. EphB receptors interact with NMDA receptors and regulate excitatory synapse formation. Cell 103: 945-956.

Dearborn Jr., R., He, Q., Kunes, S., and Dai, Y. 2002. Eph receptor tyrosine kinase-mediated formation of a topographic map in the Drosophila visual system. J. Neurosci. 22: 1338-1349.

De Bellard, M.E., Ching, W., Gossler, A., and Bronner-Fraser, M. 2002. Disruption of segmental neural crest migration and ephrin expression in delta-1 null mice. Dev. Biol. 249: 121130.

Dodelet, V.C. and Pasquale, E.B. 2000. Eph receptors and ephrin ligands: Embryogenesis to tumorigenesis. Oncogene 19: 5614-5619.

Doetsch, F., Caille, I., Lim, D.A., Garcia-Verdugo, J.M., and Alvarez-Buylla, A. 1999. Subventricular zone astrocytes are neural stem cells in the adult mammalian brain. Cell 97: 703-716.

Durbin, L., Brennan, C., Shiomi, K., Cooke, J., Barrios, A., Shanmugalingam, S., Guthrie, B., Lindberg, R., and Holder, N. 1998. Eph signaling is required for segmentation and differentiation of the somites. Genes \& Dev. 12: 3096-3109.

Eberhart, J., Swartz, M.E., Koblar, S.A., Pasquale, E.B., and Krull, C.E. 2002. EphA4 constitutes a population-specific guidance cue for motor neurons. Dev. Biol. 247: 89-101.

Ethell, I.M. and Yamaguchi, Y. 1999. Cell surface heparan sulfate proteoglycan syndecan-2 induces the maturation of dendritic spines in rat hippocampal neurons. J. Cell Biol. 144: 575-586.

Ethell, I.M., Irie, F., Kalo, M.S., Couchman, J.R., Pasquale, E.B., and Yamaguchi, Y. 2001. EphB/syndecan-2 signaling in dendritic spine morphogenesis. Neuron 31: 1001-1013.

Feldheim, D.A., Kim, Y.I., Bergemann, A.D., Frisen, J., Barbacid, M., and Flanagan, J.G. 2000. Genetic analysis of ephrin-A2 and ephrin-A5 shows their requirement in multiple aspects of retinocollicular mapping. Neuron 25: 563-574.

Feng, G., Laskowski, M.B., Feldheim, D.A., Wang, H., Lewis, R., Frisen, J., Flanagan, J.G., and Sanes, J.R. 2000. Roles for ephrins in positionally selective synaptogenesis between motor neurons and muscle fibers. Neuron 25: 295-306.

Flanagan, J.G. and Vanderhaeghen, P. 1998. The ephrins and Eph receptors in neural development. Annu. Rev. Neurosci. 21: 309-345.

Fodde, R., Smits, R., and Clevers, H. 2001. APC, signal transduction and genetic instability in colorectal cancer. Nat. Rev. Cancer 1: 55-67.

Frisen, J., Holmberg, J., and Barbacid, M. 1999. Ephrins and their Eph receptors: Multitalented directors of embryonic development. EMBO J. 18: 5159-5165.

Füller, T., Korff, T., Kilian, A., Dandekar, G., and Augustin, H.G. 2003. Forward EphB4 signaling in endothelial cells controls cellular repulsion and segregation from ephrinB2 positive cells. J. Cell Sci. 116: 2461-2470.

Gale, N.W., Baluk, P., Pan, L., Kwan, M., Holash, J., DeChiara, T.M., McDonald, D.M., and Yancopoulos, G.D. 2001. Ephrin-B2 selectively marks arterial vessels and neovascularization sites in the adult, with expression in both endothelial and smooth-muscle cells. Dev. Biol. 230: 151-160.

George, S.E., Simokat, K., Hardin, J., and Chisholm, A.D. 1998. The VAB-1 Eph receptor tyrosine kinase functions in neural and epithelial morphogenesis in C. elegans. Cell 92: 633643.

Gerety, S.S. and Anderson, D.J. 2002. Cardiovascular ephrinB2 function is essential for embryonic angiogenesis. Development 129: 1397-1410.

Gerety, S.S., Wang, H.U., Chen, Z.F., and Anderson, D.J. 1999. Symmetrical mutant phenotypes of the receptor EphB4 and its specific transmembrane ligand ephrinB2 in cardiovascular development. Mol. Cell 4: 403-414.

Gerlai, R. 2001. Eph receptors and neural plasticity. Nat. Rev. Neurosci. 2: 205-209.

Goldberg, J.L. and Barres, B.A. 2000. The relationship between neuronal survival and regeneration. Annu. Rev. Neurosci. 23: 579-612.

Grunwald, I.C., Korte, M., Wolfer, D., Wilkinson, G.A., Unsicker, K., Lipp, H.P., Bonhoeffer, T., and Klein, R. 2001. Kinase-independent requirement of EphB2 receptors in hippocampal synaptic plasticity. Neuron 32: 1027-1040.

Guthrie, S. 2001. Axon guidance: Robos make the rules. Curr. Biol. 11: R300-R303.

Hall, D.H., Winfrey, V.P., Blaeuer, G., Hoffman, L.H., Furuta, T., Rose, K.L., Hobert, O., and Greenstein, D. 1999. Ultrastructural features of the adult hermaphrodite gonad of Caenorhabditis elegans: Relations between the germ line and soma. Dev. Biol. 212: 101-123.

Harrington, R.J., Gutch, M.J., Hengartner, M.O., Tonks, N.K., and Chisholm, A.D. 2002. The C. elegans LAR-like receptor tyrosine phosphatase PTP-3 and the VAB-1 Eph receptor tyrosine kinase have partly redundant functions in morphogenesis. Development 129: 2141-2153.

Helbling, P.M., Saulnier, D.M., and Brandli, A.W. 2000. The receptor tyrosine kinase EphB4 and ephrin-B ligands restrict angiogenic growth of embryonic veins in Xenopus laevis. Development 127: 269-278.

Helmbacher, F., Schneider-Maunoury, S., Topilko, P., Tiret, L., and Charnay, P. 2000. Targeting of the EphA4 tyrosine kinase receptor affects dorsal/ventral pathfinding of limb motor axons. Development 127: 3313-3324.

Helmchen, F. 2002. Raising the speed limit-Fast $\mathrm{Ca}^{2+}$ handling in dendritic spines. Trends Neurosci. 25: 438-441.

Henderson, J.T., Georgiou, J., Jia, Z., Robertson, J., Elowe, S., 
Roder, J.C., and Pawson, T. 2001. The receptor tyrosine kinase EphB2 regulates NMDA-dependent synaptic function. Neuron 32: 1041-1056.

Henkemeyer, M., Orioli, D., Henderson, J.T., Saxton, T.M., Roder, J., Pawson, T., and Klein, R. 1996. Nuk controls pathfinding of commissural axons in the mammalian central nervous system. Cell 86: 35-46.

Hering, H. and Sheng, M. 2001. Dendritic spines: Structure, dynamics and regulation. Nat. Rev Neurosci. 2: 880-888.

Himanen, J.P., Rajashankar, K.R., Lackmann, M., Cowan, C.A., Henkemeyer, M., and Nikolov, D.B. 2001. Crystal structure of an Eph receptor-ephrin complex. Nature 414: 933-938.

Hindges, R., McLaughlin, T., Genoud, N., Henkemeyer, M., and O'Leary, D.D. 2002. EphB forward signaling controls directional branch extension and arborization required for dorsalventral retinotopic mapping. Neuron 35: 475-487.

Holder, N. and Klein, R. 1999. Eph receptors and ephrins: Effectors of morphogenesis. Development 126: 2033-2044.

Imondi, R. and Kaprielian, Z. 2001. Commissural axon pathfinding on the contralateral side of the floor plate: A role for B-class ephrins in specifying the dorsoventral position of longitudinally projecting commissural axons. Development 128: 4859-4871.

Imondi, R., Wideman, C., and Kaprielian, Z. 2000. Complementary expression of transmembrane ephrins and their receptors in the mouse spinal cord: A possible role in constraining the orientation of longitudinally projecting axons. Development 127: 1397-1410.

Irie, F. and Yamaguchi, Y. 2002. EphB receptors regulate dendritic spine development via intersectin, Cde42 and N-WASP. Nat. Neurosci. 5: 1117-1118.

Jones, T.L., Chong, L.D., Kim, J., Xu, R.H., Kung, H.F., and Daar, I.O. 1998. Loss of cell adhesion in Xenopus laevis embryos mediated by the cytoplasmic domain of XLerk, an erythropoietin-producing hepatocellular ligand. Proc. Natl. Acad. Sci. 95: 576-581.

Kalcheim, C. 2000. Mechanisms of early neural crest development: From cell specification to migration. Int. Rev. Cytol. 200: 143-196.

Kaprielian, Z., Runko, E., and Imondi, R. 2001. Axon guidance at the midline choice point. Dev. Dyn. 221: 154-181.

Karam, S.D., Burrows, R.C., Logan, C., Koblar, S., Pasquale, E.B., and Bothwell, M. 2000. Eph receptors and ephrins in the developing chick cerebellum: Relationship to sagittal patterning and granule cell migration. J. Neurosci. 20: 64886500.

Kim, I., Ryu, Y.S., Kwak, H.J., Ahn, S.Y., Oh, J.L., Yancopoulos, G.D., Gale, N.W., and Koh, G.Y. 2002. EphB ligand, ephrinB2, suppresses the VEGF- and angiopoietin 1-induced Ras/mitogen-activated protein kinase pathway in venous endothelial cells. FASEB J. 16: 1126-1128.

Klein, R. 2001. Excitatory Eph receptors and adhesive ephrin ligands. Curr. Opin. Cell Biol. 13: 196-203.

Knoll, B. and Drescher, U. 2002. Ephrin-As as receptors in topographic projections. Trends Neurosci. 25: 145-149.

Knoll, B., Isenmann, S., Kilic, E., Walkenhorst, J., Engel, S., Wehinger, J., Bahr, M., and Drescher, U. 2001a. Graded expression patterns of ephrin-As in the superior colliculus after lesion of the adult mouse optic nerve. Mech. Dev. 106: 119127.

Knoll, B., Zarbalis, K., Wurst, W., and Drescher, U. 2001b. A role for the EphA family in the topographic targeting of vomeronasal axons. Development 128: 895-906.

Koolpe, M., Dail, M., and Pasquale, E.B. 2002. An ephrin mimetic peptide that selectively targets the EphA2 receptor. J. Biol. Chem. 277: 46974-46979.
Krull, C.E., Lansford, R., Gale, N.W., Collazo, A., Marcelle, C., Yancopoulos, G.D., Fraser, S.E., and Bronner-Fraser, M. 1997. Interactions of Eph-related receptors and ligands confer rostrocaudal pattern to trunk neural crest migration. Curr. Biol. 7: 571-580.

Kullander, K. and Klein, R. 2002. Mechanisms and functions of Eph and ephrin signalling. Nat. Rev. Mol. Cell Biol. 3: 475486.

Kullander, K., Croll, S.D., Zimmer, M., Pan, L., McClain, J., Hughes, V., Zabski, S., DeChiara, T.M., Klein, R., Yancopoulos, G.D., et al. 2001a. Ephrin-B3 is the midline barrier that prevents corticospinal tract axons from recrossing, allowing for unilateral motor control. Genes \& Dev. 15: 877-888.

Kullander, K., Mather, N.K., Diella, F., Dottori, M., Boyd, A.W., and Klein, R. 2001b. Kinase-dependent and kinase-independent functions of EphA4 receptors in major axon tract formation in vivo. Neuron 29: 73-84.

Kullander, K., Butt, S.J., Lebret, J.M., Lundfald, L., Restrepo, C.E., Rydstrom, A., Klein, R., and Kiehn, O. 2003. Role of EphA4 and EphrinB3 in local neuronal circuits that control walking. Science 299: 1889-1892.

Liebl, D.J., Morris, C.J., Henkemeyer, M., and Parada, L.F. 2003. mRNA expression of ephrins and Eph receptor tyrosine kinases in the neonatal and adult mouse central nervous system. J. Neurosci. Res. 71: 7-22.

Lin, J.C. and Cepko, C.L. 1998. Granule cell raphes and parasagittal domains of Purkinje cells: Complementary patterns in the developing chick cerebellum. J. Neurosci. 18: 9342 9353.

Lu, Q., Sun, E.E., Klein, R.S., and Flanagan, J.G. 2001. Ephrin-B reverse signaling is mediated by a novel PDZ-RGS protein and selectively inhibits $G$ protein-coupled chemoattraction. Cell 105: 69-79.

Ma, Q., Jones, D., Borghesani, P.R., Segal, R.A., Nagasawa, T., Kishimoto, T., Bronson, R.T., and Springer, T.A. 1998. Impaired B-lymphopoiesis, myelopoiesis, and derailed cerebellar neuron migration in CXCR4- and SDF-1-deficient mice. Proc. Nat1. Acad. Sci. 95: 9448-9453.

Mann, F., Peuckert, C., Dehner, F., Zhou, R., and Bolz, J. 2002a. Ephrins regulate the formation of terminal axonal arbors during the development of thalamocortical projections. Development 129: 3945-3955.

Mann, F., Ray, S., Harris, W., and Holt, C. 2002b. Topographic mapping in dorsoventral axis of the Xenopus retinotectal system depends on signaling through ephrin-B ligands. Neuron 35: 461-473.

Martin, P. and Lewis, J. 1989. Origins of the neurovascular bundle: Interactions between developing nerves and blood vessels in embryonic chick skin. Int. J. Dev. Biol. 33: 379387.

McGrath, K.E., Koniski, A.D., Maltby, K.M., McGann, J.K., and Palis, J. 1999. Embryonic expression and function of the chemokine SDF-1 and its receptor, CXCR4. Dev. Biol. 213: $442-$ 456.

McLaughlin, T., Hindges, R., and O'Leary, D.D. 2003a. Regulation of axial patterning of the retina and its topographic mapping in the brain. Curr. Opin. Neurobiol. 13: 57-69.

McLaughlin, T., Hindges, R., Yates, P.A., and O'Leary, D.D. 2003b. Bifunctional action of ephrin-B1 as a repellent and attractant to control bidirectional branch extension in dorsal-ventral retinotopic mapping. Development 130: $2407-$ 2418.

Mellor, J. and Nicoll, R.A. 2001. Hippocampal mossy fiber LTP is independent of postsynaptic calcium. Nat. Neurosci. 4: 125-126.

Miao, H., Burnett, E., Kinch, M., Simon, E., and Wang, B. 2000. 
Activation of EphA2 kinase suppresses integrin function and causes focal-adhesion-kinase dephosphorylation. Nat. Cell Biol. 2: 62-69.

Miao, H., Wei, B.R., Peehl, D.M., Li, Q., Alexandrou, T., Schelling, J.R., Rhim, J.S., Sedor, J.R., Burnett, E., and Wang, B. 2001. Activation of EphA receptor tyrosine kinase inhibits the Ras/MAPK pathway. Nat. Cell Biol. 3: 527-530.

Miller, M.A., Nguyen, V.Q., Lee, M.H., Kosinski, M., Schedl, T., Caprioli, R.M., and Greenstein, D. 2001. A sperm cytoskeletal protein that signals oocyte meiotic maturation and ovulation. Science 291: 2144-2147.

Miller, M.A., Ruest, P.J., Kosinski, M., Hanks, S.K., and Greenstein, D. 2003. An Eph receptor sperm-sensing control mechanism for oocyte meiotic maturation in Caenorhabditis elegans. Genes \& Dev. 17: 187-200.

Miranda, J.D., White, L.A., Marcillo, A.E., Willson, C.A., Jagid, J., and Whittemore, S.R. 1999. Induction of Eph B3 after spinal cord injury. Exp. Neurol. 156: 218-222.

Moreno-Flores, M.T. and Wandosell, F. 1999. Up-regulation of Eph tyrosine kinase receptors after excitotoxic injury in adult hippocampus. Neuroscience 91: 193-201.

Mukouyama, Y.S., Shin, D., Britsch, S., Taniguchi, M., and Anderson, D.J. 2002. Sensory nerves determine the pattern of arterial differentiation and blood vessel branching in the skin. Cell 109: 693-705.

Murai, K.K. and Pasquale, E.B. 2002. Can Eph receptors stimulate the mind? Neuron 33: 159-162.

Murai, K.K., Nguyen, L.N., Irie, F., Yamaguchi, Y., and Pasquale, E.B. 2003. Control of hippocampal dendritic spine morphology through ephrin-A3/EphA4 signaling. Nat. Neurosci. 6: 153-160.

Nakagawa, S., Brennan, C., Johnson, K.G., Shewan, D., Harris, W.A., and Holt, C.E. 2000. Ephrin-B regulates the ipsilateral routing of retinal axons at the optic chiasm. Neuron 25: 599610.

Nakamoto, M. and Bergemann, A.D. 2002. Diverse roles for the Eph family of receptor tyrosine kinases in carcinogenesis. Microsc. Res. Tech. 59: 58-67.

Naruse-Nakajima, C., Asano, M., and Iwakura, Y. 2001. Involvement of EphA2 in the formation of the tail notochord via interaction with ephrinA1. Mech. Dev. 102: 95-105.

Nebreda, A.R. and Ferby, I. 2000. Regulation of the meiotic cell cycle in oocytes. Curr. Opin. Cell Biol. 12: 666-675.

Newsome, T.P., Schmidt, S., Dietzl, G., Keleman, K., Asling, B., Debant, A., and Dickson, B.J. 2000. Trio combines with dock to regulate Pak activity during photoreceptor axon pathfinding in Drosophila. Cell 101: 283-294.

Nishida, K., Flanagan, J.G., and Nakamoto, M. 2002. Domainspecific olivocerebellar projection regulated by the EphAephrin-A interaction. Development 129: 5647-5658.

Nomura-Kitabayashi, A., Takahashi, Y., Kitajima, S., Inoue, T., Takeda, H., and Saga, Y. 2002. Hypomorphic Mesp allele distinguishes establishment of rostrocaudal polarity and segment border formation in somitogenesis. Development 129: 2473-2481.

Ogawa, K., Pasqualini, R., Lindberg, R.A., Kain, R., Freeman, A.L., and Pasquale, E.B. 2000. The ephrin-A1 ligand and its receptor, EphA2, are expressed during tumor neovascularization. Oncogene 19: 6043-6052.

O'Leary, D.D. and Wilkinson, D.G. 1999. Eph receptors and ephrins in neural development. Curr. Opin. Neurobiol. 9: 65-73.

Palmer, A., Zimmer, M., Erdmann, K.S., Eulenburg, V., Porthin, A., Heumann, R., Deutsch, U., and Klein, R. 2002. EphrinB phosphorylation and reverse signaling: Regulation by Src kinases and PTP-BL phosphatase. Mol. Cell 9: 725-737.
Penzes, P., Beeser, A., Chernoff, J., Schiller, M.R., Eipper, B.A., Mains, R.E., and Huganir, R.L. 2003. Rapid Induction of dendritic spine morphogenesis by trans-synaptic ephrinB-EphB receptor activation of the Rho-GEF kalirin. Neuron 37: 263 274

Pickles, J.O. and van Heumen, W.R. 1997. The expression of messenger RNAs coding for growth factors, their receptors, and eph-class receptor tyrosine kinases in normal and ototoxically damaged chick cochleae. Dev. Neurosci. 19:476487.

Pittman, A. and Chien, C.B. 2002. Understanding dorsoventral topography: Backwards and forwards. Neuron 35: 409-411.

Prakash, N., Vanderhaeghen, P., Cohen-Cory, S., Frisen, J., Flanagan, J.G., and Frostig, R.D. 2000. Malformation of the functional organization of somatosensory cortex in adult ephrin-A5 knock-out mice revealed by in vivo functional imaging. J. Neurosci. 20: 5841-5847.

Pratt, R.L. and Kinch, M.S. 2002. Activation of the EphA2 tyrosine kinase stimulates the MAP/ERK kinase signaling cascade. Oncogene 21: 7690-7699.

Risau, W. 1997. Mechanisms of angiogenesis. Nature 386: 671674.

Rodger, J., Bartlett, C.A., Beazley, L.D., and Dunlop, S.A. 2000. Transient up-regulation of the rostrocaudal gradient of ephrin $\mathrm{A} 2$ in the tectum coincides with reestablishment of orderly projections during optic nerve regeneration in goldfish. Exp. Neurol. 166: 196-200.

Rodger, J., Lindsey, K.A., Leaver, S.G., King, C.E., Dunlop, S.A., and Beazley, L.D. 2001. Expression of ephrin-A2 in the superior colliculus and EphA5 in the retina following optic nerve section in adult rat. Eur. J. Neurosci. 14: 1929-1936.

Ruoslahti, E. 1999. Fibronectin and its integrin receptors in cancer. Adv. Cancer Res. 76: 1-20.

Saga, Y., Hata, N., Koseki, H., and Taketo, M.M. 1997. Mesp2: A novel mouse gene expressed in the presegmented mesoderm and essential for segmentation initiation. Genes \& Dev. 11: 1827-1839.

Santiago, A. and Erickson, C.A. 2002. Ephrin-B ligands play a dual role in the control of neural crest cell migration. Development 129: 3621-3632.

Schmidt, C., Christ, B., Maden, M., Brand-Saberi, B., and Patel, K. 2001. Regulation of Epha4 expression in paraxial and lateral plate mesoderm by ectoderm-derived signals. Dev. Dyn. 220: $377-386$.

Sestan, N., Rakic, P., and Donoghue, M.J. 2001. Independent parcellation of the embryonic visual cortex and thalamus revealed by combinatorial Eph/ephrin gene expression. Curr. Biol. 11: 39-43.

Shin, D., Garcia-Cardena, G., Hayashi, S., Gerety, S., Asahara, T., Stavrakis, G., Isner, J., Folkman, J., Gimbrone Jr., M.A., and Anderson, D.J. 2001. Expression of ephrinB2 identifies a stable genetic difference between arterial and venous vascular smooth muscle as well as endothelial cells, and marks subsets of microvessels at sites of adult neovascularization. Dev. Biol. 230: 139-150.

Stein, E., Lane, A.A., Cerretti, D.P., Schoecklmann, H.O., Schroff, A.D., Van Etten, R.L., and Daniel, T.O. 1998. Eph receptors discriminate specific ligand oligomers to determine alternative signaling complexes, attachment, and assembly responses. Genes \& Dev. 12: 667-678.

Stuckmann, I., Weigmann, A., Shevchenko, A., Mann, M., and Huttner, W.B. 2001. Ephrin B1 is expressed on neuroepithelial cells in correlation with neocortical neurogenesis. $J$. Neurosci. 21: 2726-2737.

Symonds, A.C., Rodger, J., Tan, M.M., Dunlop, S.A., Beazley, L.D., and Harvey, A.R. 2001. Reinnervation of the superior 
colliculus delays down-regulation of ephrin A2 in neonatal rat. Exp. Neurol. 170: 364-370.

Takasu, M.A., Dalva, M.B., Zigmond, R.E., and Greenberg, M.E. 2002. Modulation of NMDA receptor-dependent calcium influx and gene expression through EphB receptors. Science 295: 491-495.

Tepass, U., Godt, D., and Winklbauer, R. 2002. Cell sorting in animal development: Signalling and adhesive mechanisms in the formation of tissue boundaries. Curr. Opin. Genet. Dev. 12: 572-582.

Tong, J., Elowe, S., Nash, P., and Pawson, T. 2003. Manipulation of EphB2 regulatory motifs and $\mathrm{SH} 2$ binding sites switches MAPK signaling and biological activity. J. Biol. Chem. 278: 6111-6119.

Uziel, D., Muhlfriedel, S., Zarbalis, K., Wurst, W., Levitt, P., and Bolz, J. 2002. Miswiring of limbic thalamocortical projections in the absence of ephrin-A5. J. Neurosci. 22: 9352 9357.

Vanderhaeghen, P., Lu, Q., Prakash, N., Frisen, J., Walsh, C.A., Frostig, R.D., and Flanagan, J.G. 2000. A mapping label required for normal scale of body representation in the cortex. Nat. Neurosci. 3: 358-365.

van de Wetering, M., Sancho, E., Verweij, C., de Lau, W., Oving, I., Hurlstone, A., van der Horn, K., Batlle, E., Coudreuse, D., Haramis, A.P., et al. 2002. The $\beta$-catenin/TCF-4 complex imposes a crypt progenitor phenotype on colorectal cancer cells. Cell 111: 241-250.

Wang, H.U. and Anderson, D.J. 1997. Eph family transmembrane ligands can mediate repulsive guidance of trunk neural crest migration and motor axon outgrowth. Neuron 18: 383 396.

Wang, H.U., Chen, Z.-F., and Anderson, D.J. 1998. Molecular distinction and angiogenic interaction between embryonic arteries and veins revealed by ephrin-B2 and its receptor EphB4. Cell 93: 741-753.

Wilkinson, D.G. 2000. Topographic mapping: Organising by repulsion and competition? Curr. Biol. 10: R447-R451.

- 2001. Multiple roles of EPH receptors and ephrins in neural development. Nat. Rev. Neurosci. 2: 155-164.

Winning, R.S., Scales, J.B., and Sargent, T.D. 1996. Disruption of cell adhesion in Xenopus embryos by Pagliaccio, an Ephclass receptor tyrosine kinase. Dev. Biol. 179: 309-319.

Wizenmann, A., Thies, E., Klostermann, S., Bonhoeffer, F., and Bahr, M. 1993. Appearance of target-specific guidance information for regenerating axons after CNS lesions. Neuron 11: 975-983.

Yates, P.A., Roskies, A.L., McLaughlin, T., and O'Leary, D.D. 2001. Topographic-specific axon branching controlled by ephrin-As is the critical event in retinotectal map development. J. Neurosci. 21: 8548-8563.

Yokoyama, N., Romero, M.I., Cowan, C.A., Galvan, P., Helmbacher, F., Charnay, P., Parada, L.F., and Henkemeyer, M. 2001. Forward signaling mediated by ephrin-B3 prevents contralateral corticospinal axons from recrossing the spinal cord midline. Neuron 29: 85-97.

Yue, Y., Chen, Z.Y., Gale, N.W., Blair-Flynn, J., Hu, T.J., Yue, X., Cooper, M., Crockett, D.P., Yancopoulos, G.D., Tessarollo, L., et al. 2002. Mistargeting hippocampal axons by expression of a truncated Eph receptor. Proc. Natl. Acad. Sci. 99: 10777-10782.

Zantek, N.D., Azimi, M., Fedor-Chaiken, M., Wang, B., Brackenbury, R., and Kinch, M.S. 1999. E-cadherin regulates the function of the EphA2 receptor tyrosine kinase. Cell Growth Differ. 10: 629-638.

Zelinski, D.P., Zantek, N.D., Stewart, J.C., Irizarry, A.R., and Kinch, M.S. 2001. EphA2 overexpression causes tumorigen- esis of mammary epithelial cells. Cancer Res. 61: 23012306.

Zou, Y.R., Kottmann, A.H., Kuroda, M., Taniuchi, I., and Littman, D.R. 1998. Function of the chemokine receptor CXCR4 in haematopoiesis and in cerebellar development. Nature 393: 595-599. 


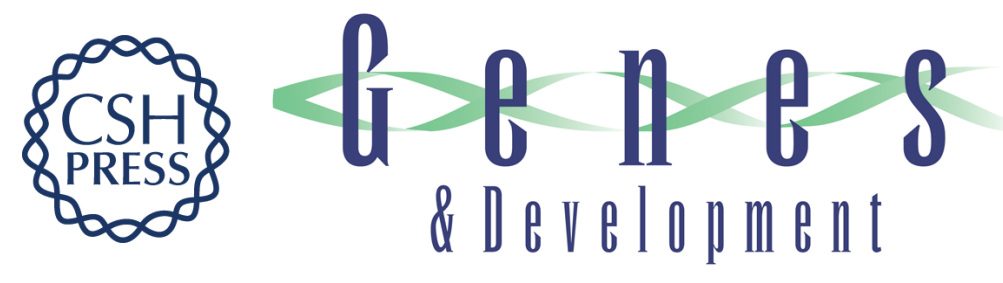

\section{Multiple roles of ephrins in morphogenesis, neuronal networking, and brain function}

Amparo Palmer and Rüdiger Klein

Genes Dev. 2003, 17:

Access the most recent version at doi:10.1101/gad.1093703

References This article cites 136 articles, 42 of which can be accessed free at: http://genesdev.cshlp.org/content/17/12/1429.full.html\#ref-list-1

License

Email Alerting

Receive free email alerts when new articles cite this article - sign up in the box at the top Service right corner of the article or click here.

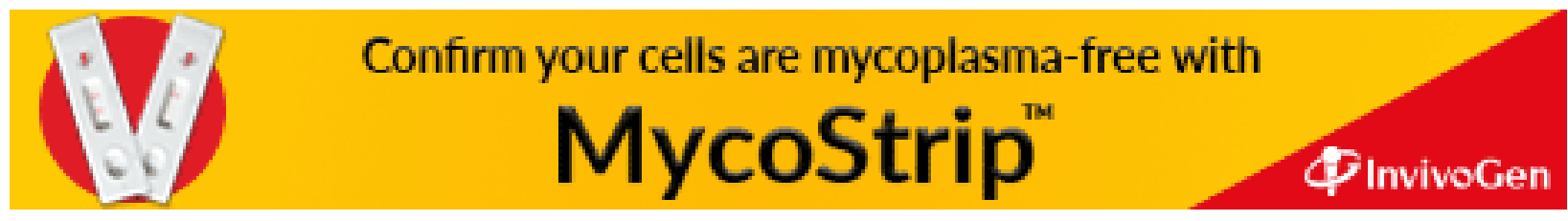

